Arqueología y Sociedad,

№ 19,2008

\title{
TUPE: UN PUEBLO DETENIDO EN EL TIEMPO
}

\author{
Al maestro y amigo José Antonio Del Busto Durthuburu
}

\author{
Luisa Vetter Parodi* \\ Martin MacKay Fulle**
}

\section{Resumen}

En la cuenca del río Cañete, departamento de Lima, se encuentra el pueblo de Tupe. Su historia es prácticamente desconocida pues es poco lo que se conoce de su pasado precolombino a pesar de la existencia de varios sitios arqueológicos. Su población ha conservado el idioma y vestimenta nativos. En esta última destaca de manera particular el uso de los tupus o prendedores prehispánicos que se pensaba habían dejado de usarse en el siglo XIX.

\section{Palabras clave}

Tupe, pictografías, vestimenta, tupu, jaqaru.

\begin{abstract}
Tupe is located at the drainage of Cañete River, Department of Lima, Peru. Most of its pre-Columbian history remains unknown even though there are many archaeological sites surrounding it. Its language (jaqaru) and traditional dress have been preserved. One of the most distinctive features of clothing is the use of tupus or prehispanic pins which were thought to be lost in nineteenth century.
\end{abstract}

\section{Keywords}

Tupe, pictigraphy, dress, tupu, jaqaru.

\footnotetext{
* Pontificia Universidad Católica del Perú. Correo electrónico: luchivetter@hotmail.com

* Director de la Sección de Arqueología, Instituto Riva Agüero, Pontificia Universidad Católica del Perú. Correo electrónico: arqueo73@hotmail.com
} 


\section{INTRODUCCIÓN}

El anhelo de los arqueólogos y antropólogos es encontrar un asentamiento donde las costumbres ancestrales aún se encuentren vigentes pues esto les permitirá un viaje al pasado en donde podríamos observar a una población siguiendo sus costumbres como si el tiempo no hubiese transcurrido. El estudio de la población y su cultura sobre la base de la interpretación del material arqueológico ya no sería necesario, pues los tenemos allí, realizándose en el instante mismo de nuestro estudio.

La arqueología no es una ciencia exacta ya que se basa en la interpretación, en algunos casos a priori, del material arqueológico que el investigador encuentra en sus excavaciones. A veces el arqueólogo encuentra vacíos en el material, lo que dificulta su trabajo en el gabinete. En el caso que el investigador se halle frente a frente con un asentamiento "congelado" en el tiempo, el material cultural estará intacto, pero la interpretación será quizás más ardua, ya que tenemos que lidiar con elementos como el lenguaje y expresiones de la gente que quieren contar su historia; esta forma de contar la historia podría resultar más complicada de interpretar que el material arqueológico mismo. El anhelo aludido se hace realidad al visitar el pueblo de Tupe.

A partir de nuestras investigaciones sobre los tupus, topos o prendedores prehispánicos (Vetter 2004, 2007), nos interesamos particularmente en la manera cómo este elemento era utilizado para sujetar la lliclla o manta de la mujer andina. Por ello, llamó nuestra atención encontrar en una revista una fotografía donde aparecía una mujer contemporánea con una vestimenta negra de ribetes rojos y luciendo unos hermosos tupus de plata en el pecho (Velarde 2002). El artículo presentaba al pueblo de Tupe, muy cerca de la ciudad de Lima; la posibilidad de encontrar en uso en pleno siglo XXI un elemento de origen prehispánico nos motivó a viajar hacia este pue- blo donde aún se conservan algunas costumbres prehispánicas como el uso del tupu que se creyó perdido en el siglo XIX, y donde aún se habla la lengua jaqaru casi desconocida en nuestros días. En la década de 1950, José Matos Mar de Julio C. Tello-motivó a sus estudiantes a recopilar información etnográfica (Ávalos de Matos 1952, Delgado de Thays 1959) y lingüística (Hardman 1983, aunque su trabajo se realizó en 1957) de este sitio.

\section{UBICACIÓN GEOGRÁFICA Y CARACTERIZACIÓN}

Tupe se encuentra ubicado en la provincia de Yauyos, a $240 \mathrm{kms}$. al SE de la ciudad de Lima, la capital del Perú. Está ubicado a 2,840 msnm, en zona de sierra, y tiene una población de 800 habitantes aproximadamente. Otros dos anexos forman parte de él: Aiza y Colca. Estos poblados se encuentran a una distancia aproximada de dos horas a pie. La fundación española tuvo lugar en 1562 por don Diego Dávila Briceño, Corregidor de Yauyos, con el objeto de extirpar las idolatrías en las etnias de Sh'ucho (Cachuy), siendo bautizado con el nombre de San Bartolomé de Tupi (Fig. 1 y 2).

Para llegar a Tupe se sigue la carretera Panamericana Sur desde Lima, y en Cañete $(\mathrm{km}$. 130 aproximadamente) se toma el desvío hacia Imperial y se sube por el camino de Lunahuaná hasta Catahuasi (este tramo del viaje dura aproximadamente dos horas y media). Un kilómetro después de Catahuasi se encuentra un desvío a la derecha por donde se inicia la subida. Luego de media hora se llega a Mitarkipa, donde actualmente se hacen los trabajos de construcción de la "carretera" - camino empedrado- que llegará hasta Aiza, y quizás alcance el propio Tupe. Aquí encontramos la imagen de una pequeña Virgen con su altar de piedra y algunas construcciones de calaminas que sirven como refugio a los obreros y guardianes de la obra, así como depósitos para los materiales y herramientas de la construcción. Hasta este 




Figura 1. Ubicación de Tupe en el mapa realizado por Diego Dávila Briceño en 1586.

punto llega el automóvil. A partir de aquí es necesario contratar bestias de carga y para ello se debe llamar por teléfono previamente a Tupe para solicitarlas. La caminata hasta el pueblo demora alrededor de 3 horas para los lugareños, pero para un visitante cualquiera podría demorar entre 5 y 6 horas. El trayecto desde Mitarkipa hasta Aiza es tranquilo y la pendiente muy suave, pero las cosas cambian en el tramo de Aiza hacia Tupe. El camino ya no es solamente tierra apisonada, encontramos piedras de distinta forma y tamaño que dificultan el trayecto; además la subida se vuelve más empinada y el camino se va perdiendo en algunos tramos. Unos 500 metros antes de llegar a Tupe, se sube una cuesta de piedras y barro, adyacente a un riachuelo, se pasa por un puente y se sigue por una pequeña subida hasta llegar al pueblo. El viaje de regreso es más tranquilo, ya que es de bajada y se puede hacer desde Tupe hasta Mitarkipa en un lapso de horas a paso ligero.

Tupe se encuentra al lado de una quebrada profunda, en la unión de dos ríos: Chancay (lado sur hacia el cerro Tupinachaca) y el río Uchapaya (lado norte); ambos se unen al inicio del pueblo creando de esta forma el río Tupe.

El tramo desde Catahuasi hasta Aiza es árido y sumamente escarpado; se observan pocos andenes en el camino, única forma posible de cultivo en la zona. En cambio, el área que se extiende desde Aiza hasta Tupe es mucho más propicia para la agricultura y ganadería. En el camino se observan numerosos andenes, algunos de los cuales no miden más de $1 \mathrm{~m}$. de ancho. Los cultivos principales son maíz, papa y alfalfa, esta última como alimento para el ganado vacuno, ovino y caprino. Otro producto importante es el queso que preparan para ser comercializa- 


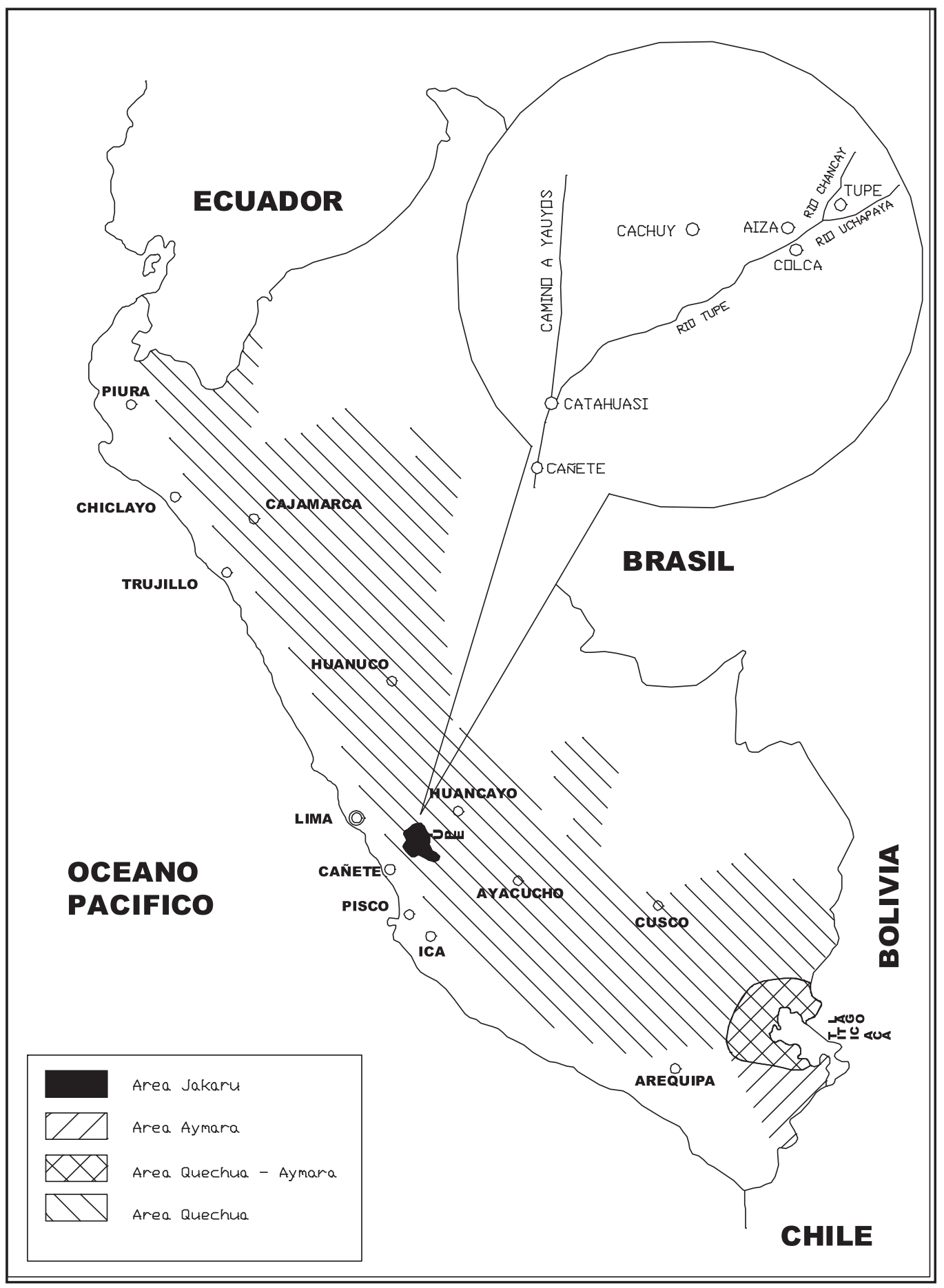

Figura 2. 
do. Las casas de Tupe han sido construidas con piedras y el techo es de calamina. Cuando una casa se derrumba, la abandonan y proceden a construir otra, lo que hace que las casas en desuso parezcan restos arqueológicos ubicados dentro del área habitada (Fig. 3).

Entre las 6 am y 11 am las tupinas realizan labores domésticas como la preparación de alimentos y la limpieza. Los hombres salen desde temprano a sus chacras o a pastar el ganado, y regresan a las 6 de la tarde. A partir de las 11 de la mañana ellas se unen a estas labores. Las chacras se encuentran a distancias hasta de una hora o más a pie. Por ello, durante gran parte del día, Tupe parece un pueblo fantasma, no camina nadie por las calles, solo se ve de vez en cuando a algún niño jugando. Las pequeñas bo- degas que se encuentran en el pueblo también cierran sus puertas durante esas horas.

La lengua nativa es el jaqaru, pero también se habla el castellano. Los niños aprenden en casa primero el castellano y luego en la escuela aprenden el jaqaru. La población tiene acceso a educación inicial, primaria y secundaria; y es importante señalar que hay un gran esfuerzo en la educación de este pueblo, lo que se traduce en el desarrollo de una educación bilingüe que permite conservar el jaqaru, si bien ahora es una segunda lengua para los tupinos. Sin embargo, debemos mencionar que los adultos hablan entre sí en jaqaru. Los tres pueblos (Tupe, Aiza y Colca) procuran mantener sus costumbres intactas, tanto en la lengua como en la vestimenta. Antes Catahuasi era parte del



Figura 3. Arquitectura típica de Tupe. 
distrito de Tupe, pero ahora se ha convertido en distrito y no conserva ni el idioma ni la vestimenta típica, quizás por su cercanía con poblaciones hispanohablantes. Es posible que por encontrarse más alejado, Tupe haya conservado el uso del anako y los tupus entre las ancianas, mientras que en los anexos más cercanos a otros pueblos-ya no se usan.

\section{TUPE PREHISPÁNICO}

Hablar de la historia de Tupe, previa a la conquista española, es tan difícil como referirnos a la historia de todos los pueblos enclavados en las nacientes de los valles de la costa peruana. Debido a las dificultades del trabajo de campo en sitios de altura, la falta de arquitectura monumental en el área y la propia desidia de los arqueólogos, la arqueología no ha prestado el interés debido a la zona de las nacientes de los valles costeños, particularmente aquellos de la costa central; por ello cualquier investigación sobre el tema debe iniciarse a partir de la etnohistoria y las fuentes españolas escritas durante la conquista y los primeros años de la colonia, entre los siglos XVI y XVII.

San Bartolomé de Tupe o Tupi está ubicado en una zona

Figura 4. El cerro Tupinachaca, Apu principal de los tupinos. de pequeños ríos que alimentan la naciente del valle de Cañete y que, gracias a los estudios de Pedro Villar Córdova (1935) y de María Rostworowski (2002: 206) sobre la base de documentos del primer Corregidor de Yauyos, don Diego Dávila Briceño, sabemos fue el área nuclear del pueblo Yauyo, sociedad del Intermedio Tardío (1000-1400 d.C.) que extendió su territorio hacia las cabeceras de los valles de Lurín, Rímac (Huarochirí) y Chillón
(Canta), transformándose en el intermediario del contacto entre las sociedades del litoral y las de puna.

De esta manera, los yauyos difundieron su cultura en las serranías del actual departamento de Lima, dejando como testimonio dos elementos importantes: su lengua, el cauqui o jaqaru (según Tello el A'Karo) y su arquitectura caracterizada por estructuras denominadas por el padre Villar Córdova (1935: 357) como "mastabas".

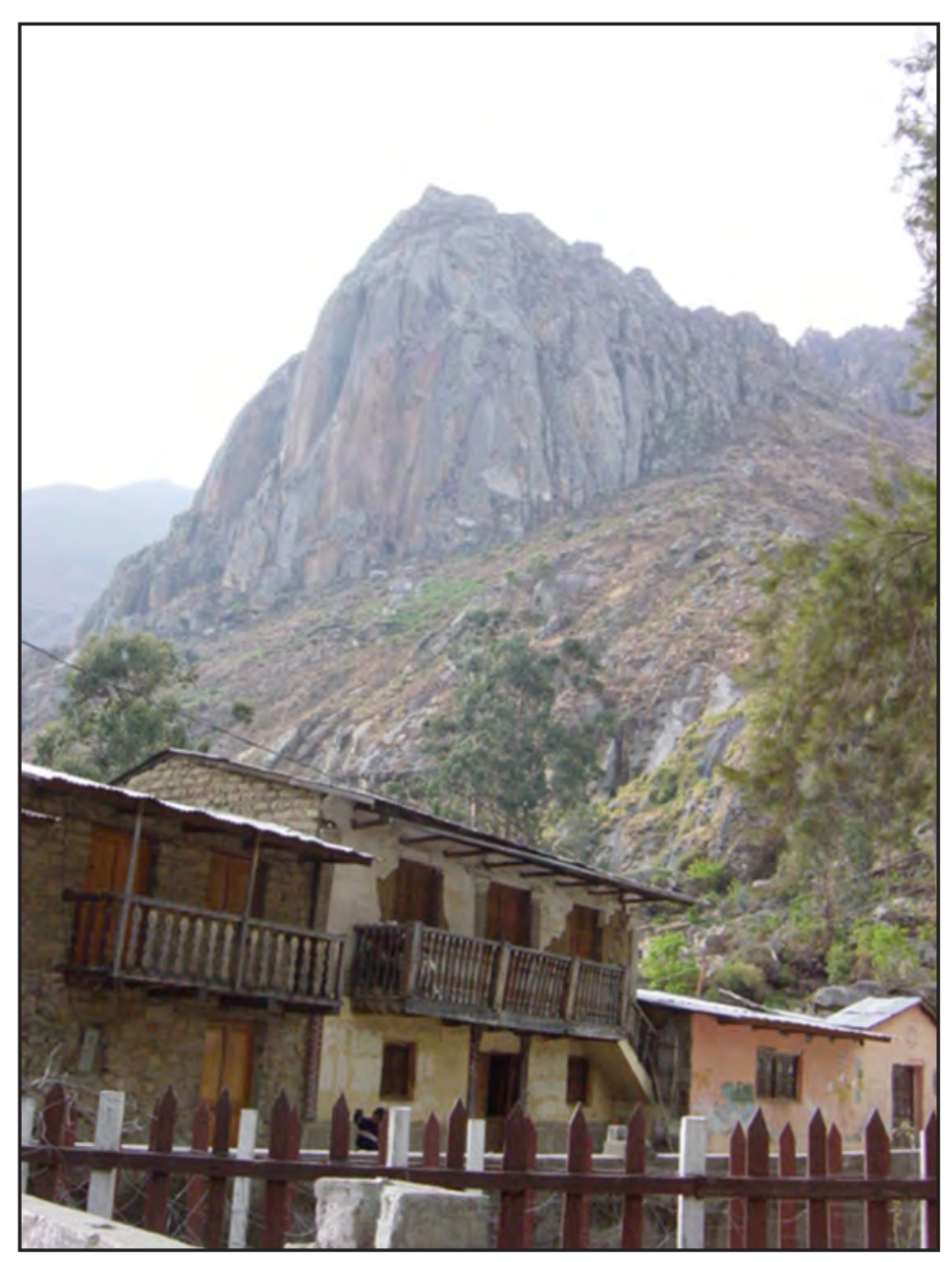


Estas se encontraban ubicadas en tres sitios: Tupinachaca, Mallma y Umay. Actualmente sabemos que estas "mastabas" son cistas funerarias hechas de piedra canteada sin labrar y con uso ocasional de mortero de barro.

Julio C. Tello realizó excavaciones en la zona; lamentablemente estos trabajos nunca fueron publicados y los materiales recuperados se perdieron en los depósitos de distintos museos. Sin embargo, sabemos por notas del sabio peruano (Matos Mar 1956: 8) que entre los materiales hallados se encontraban ceramios, instrumentos de plata, cobre y bronce (entre ellos tupus) y gran cantidad de textilería. Casi todo este material fue asociado por Tello a culturas costeñas vecinas de los valles de Cañete, Pisco y Chincha pero sobre todo al estilo Tiahuanaco (ibid.). Recordemos que en aquellos años, Tiahuanaco o tiahuanacoide era la denominación de lo que hoy son los distintos estilos cerámicos del Horizonte Medio (600 - 1000 d.C.).

El sitio de Tupinachaca se encuentra a más de $1 \mathrm{~km}$ al noroeste del poblado de Tupe, en la parte media del cerro que le da nombre. El Tupinachaca es reverenciado por la población actual como Apu, lo que es fácil de entender pues es una de las grandes cumbres que rodea el pueblo, con una altura de 3840 msnm, y además desliza las aguas del río Chancay hacia el poblado (Fig. 4). En la parte media del cerro encontramos tres sectores del sitio arqueológico descrito por Villar Córdova (1935).

\section{Sector I. Cistas funerarias}

El primer sector es un conjunto de cistas funerarias ubicadas en pequeños abrigos rocosos o cavernas naturales de no más de 4 a $5 \mathrm{~m}$ de profundidad, en la cara sur del cerro Tupinachaca, con sus entradas orientadas hacia el río Uchapaya. Su arquitectura es muy sencilla, en base a piedra canteada sin labrar, colocada prácticamente sin mortero y formando una planta cuadrangular que ocupa toda la superfi-

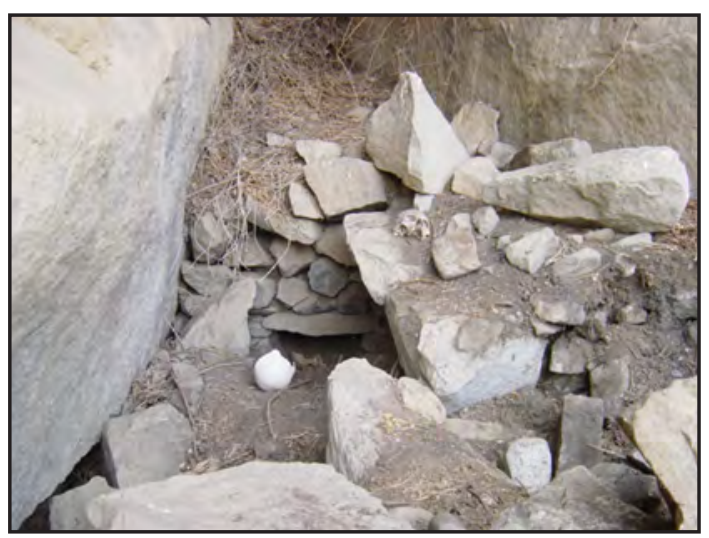

Figura 5. Cistas funerarias ubicadas en el Tupinachaca.

cie del abrigo rocoso. (Fig. 5)

Estas cistas tienen una altura no mayor de $1.50 \mathrm{~m}$; sin embargo gran parte de la estructura se encuentra bajo tierra, por lo que consideramos a esta forma de enterramiento como semisubterráneo. El tipo de construcción funeraria ha impedido que muchas de las tumbas hayan sido totalmente saqueadas. A pesar de sus dimensiones pequeñas, las cistas de Tupinachaca son comparables en ciertos patrones a todas aquellas estructuras funerarias ubicadas en las cabeceras de los valles del Chillón y Rímac (Cantamarca, Chipprak, San Pedro de Casta, San Juan de Iris, etc.).

Según datos de Villar Córdova, de los propios pobladores de Tupe y de nuestras propias observaciones, los cuerpos fueron colocados dentro de las cistas en posición sentado-flexionada, siendo su estado de conservación muy bueno. De acuerdo a los restos óseos observados, estas cistas podrían haberse utilizado durante un lapso prolongado de tiempo, ya que se depositó gran cantidad de individuos en cada una de ellas. Los cuerpos corresponden a ambos sexos y un amplio rango de edad.

Es sumamente importante mencionar que estos contextos funerarios se encuentran asociados a una gran cantidad de terrazas que muy probablemente habrían servido como base de las viviendas de los antiguos pobladores del 


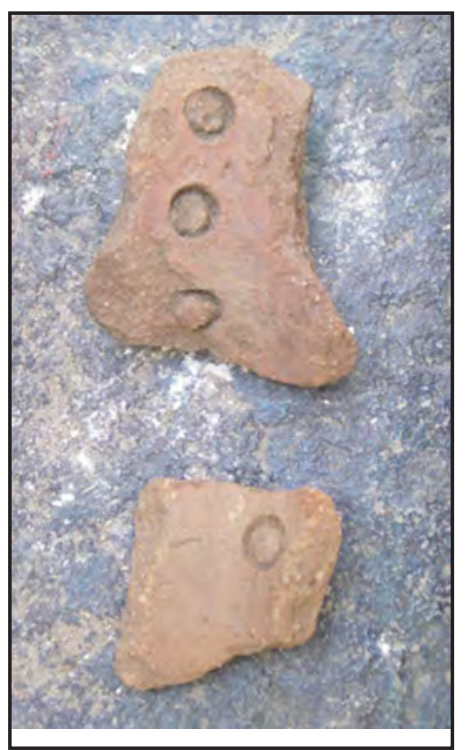

lugar. Esta idea se refuerza porque desde este sector se observa y controla las zonas de cultivo con andenería que son irrigadas por los ríos Uchapaya y Chancay, y que son la fuente de alimento de los actuales pobladores de Tupe y probablemente también de los antiguos pobladores del Tupinachaca. Además, en toda el área se encuentra en superficie gran cantidad de fragmentos de cerámica utilitaria, mayormente ollas con hollín y cántaros (Fig. 6). Existen también evidencias de instrumentos líticos como morteros, manos de moler y pequeños instrumentos hechos de cantos rodados.

Más importante aún nos parece la evidencia de la ausencia de separación espacial entre muertos y vivos; la "ve-

Figura 7. Vista general de las pictografías.
Figura 6. Cerámica prehispánica asociada a estructuras en el Apu.

cindad" entre tumbas y hogares ilustra la necesidad de integrar al individuo fallecido -transformado en ancestro- a la comunidad. Se suma a esto la integración entre el Apu Tupinachaca y los ancestros: es evidente la intención de que quien fallece "ingrese" o "se encuentre", mediante su enterramiento en cistas al interior de abrigos rocosos, con la deidad tutelar del pueblo.

\section{Sector II. Pictografías}

El segundo sector del área arqueológica de Tupe está compuesto por un conjunto de pinturas rupestres o pictografías sobre un farallón natural de la misma ladera sur del Tupinachaca, donde se encuentran las estructuras fu- nerarias. Las pinturas se pueden observar desde el mismo pueblo debido a su excelente ubicación y a la conformación natural del farallón rocoso, el cual es prácticamente vertical y tiene cerca de $15 \mathrm{~m}$ de altura. Estas imágenes han sido pintadas casi en su totalidad con algún instrumento tipo brocha o con las propias manos. El color de los diseños es ocre rojo (solo una pintura está acompañada de un pigmento blanco) obtenido de algún elemento con óxido de hierro. En el caso de los escasos pigmentos blancos, quizá hayan sido elaborados con arcilla líquida. (Fig. 7)

Las pictografías se encuentran a una altura que supera los $2 \mathrm{~m}$, lo cual nos llevó a pensar en la construcción previa de andamios para pintar los diseños, utilizando grandes piedras existentes en la base

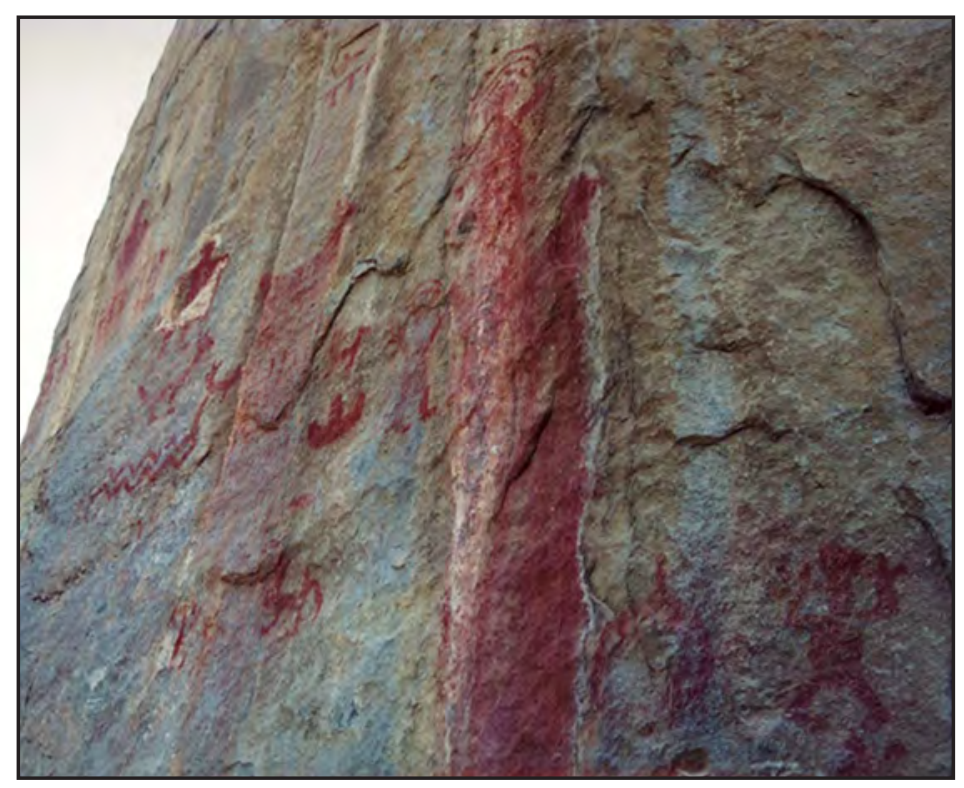




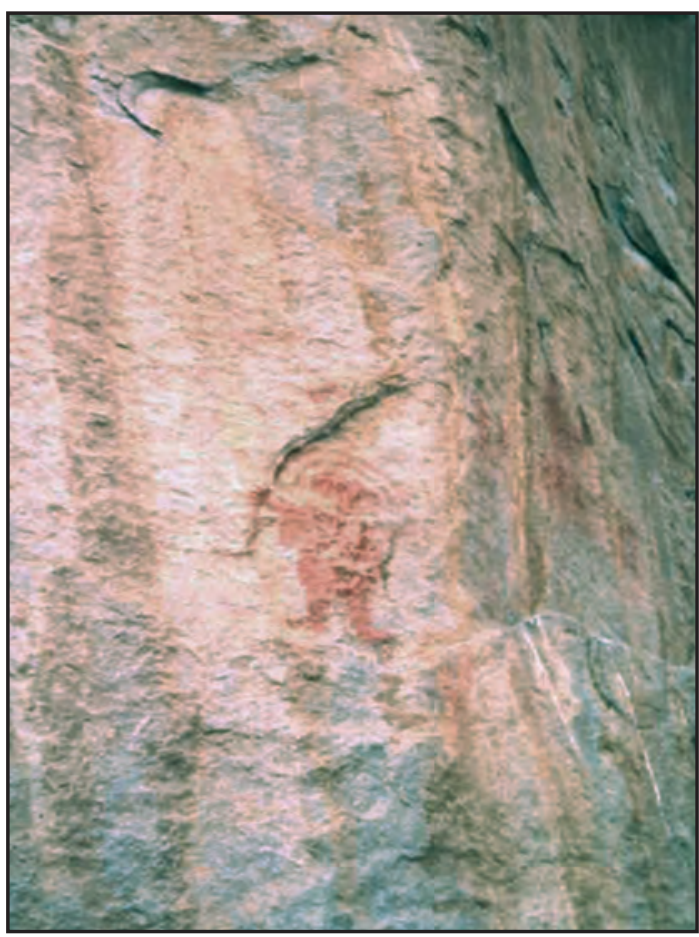

Figura 8. Grupo de pictografías No 1.

del farallón, que por su disposición habrían servido como escalones, y en algunos casos llegan a la altura donde se ubican los diseños. Además, todos estos dibujos están rodeados de bases de estructuras de piedra canteada muy sencillas, las cuales conformaron plataformas donde debieron realizarse actividades rituales, o en todo caso sirvieron como sostén de estructuras perecibles.

Las pinturas se encuentran aparentemente aglutinadas, pero con algo de paciencia se puede aislar un grupo de conjuntos y categorías de dibujos.

Observando de izquierda a derecha podemos definir los siguientes grupos:

1. Personaje antropomorfo de brazos extendidos, con tocado tipo "arco iris". (Fig. 8)

2. Personaje antropomorfo que tiene a sus pies otros personajes similares de menor

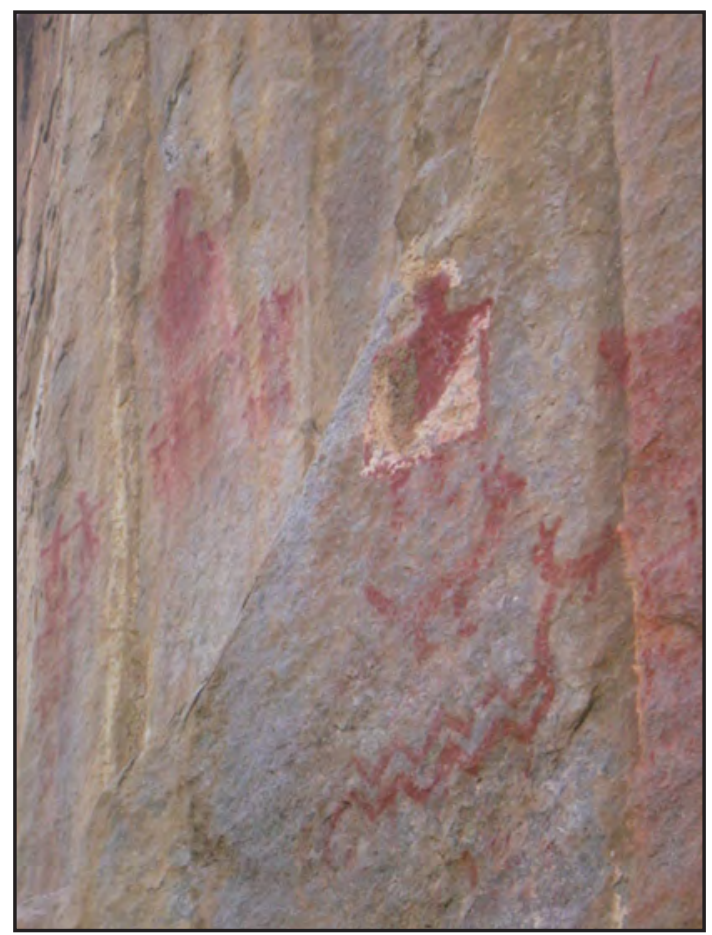

Figura 9. Grupo de pictografías No 2.

tamaño, con brazos extendidos y evidentes miembros masculinos. Estos personajes menores están acompañados por probables camélidos. (Fig. 9).

3. Tres personajes antropomorfos de brazos extendidos con tocado tipo "arco iris". Uno de ellos lleva un unku bicolor o camisa cuadrangular sin mangas, con cuello generalmente en "V". En el segmento inferior se observan posibles camélidos dirigiéndose tanto al oeste como al este, y un símbolo ondulante que los lugareños denominan "la serpiente", aunque es posible que se trate de un símbolo que señale movimiento de líquido. Otro símbolo es conocido como "el bote", pero más bien se trata de una especie de cuchillo ceremonial o tumil. En la parte superior de toda esta escena se puede observar un ave con las alas

1 El tumi o cuchillo ceremonial de los Andes se caracteriza por la hoja de metal en forma de media luna. Fue usado con fines rituales. 


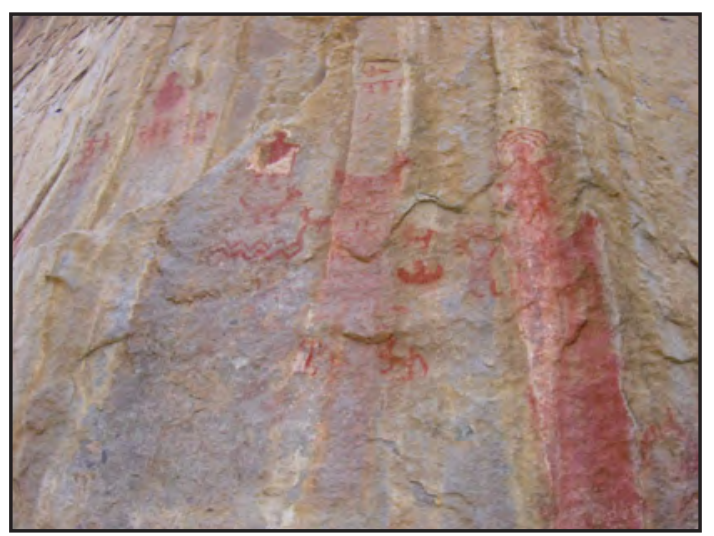

Figura 10. Grupo de pictografías No 3.

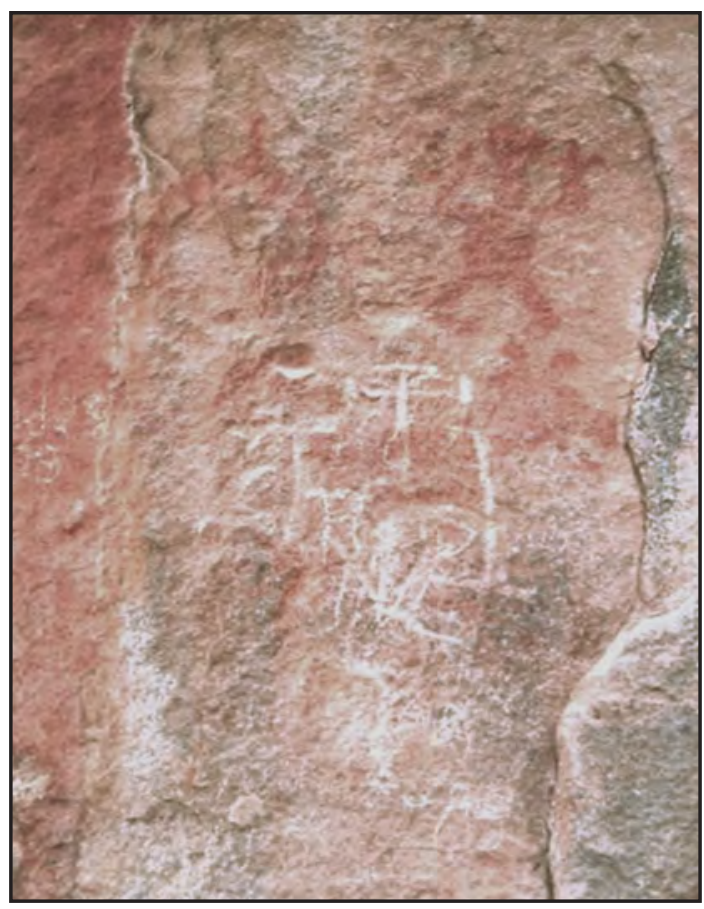

Figura 11. Grupo de pictografías No 4.

desplegadas y debajo de ella un símbolo a base de franjas. (Fig. 10).

4. Personaje antropomorfo con tocado con "plumas" o "pelos erizados". Está acompañado de dos grandes camélidos (que al parecer están en movimiento, a diferencia de otros) y un círculo a su lado derecho. (Fig. 11).

5. Al menos cuatro personajes antropomorfos pequeños, muy similares a los descritos en el

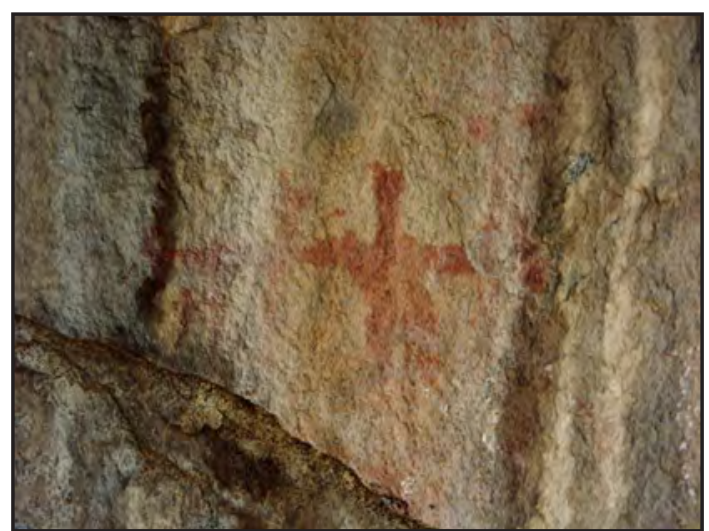

Figura 12. Grupo de pictografías No 5.

párrafo anterior, aunque muy borrosos. Uno de ellos sujeta a un probable camélido. Esta escena se encuentra en una pared, a la derecha del resto de escenas, en una zona baja, a tan solo $1.50 \mathrm{~m}$ de la superficie. (Fig. 12)

Estos diseños pueden ser clasificados en tres tipos:

- Diseños antropomorfos:

a. Grandes, con tocados, brazos extendidos y asexuados.

b. Pequeños, con brazos extendidos y miembro masculino.

\section{- Diseños zoomorfos:}

a. Camélidos pequeños en posición estática (ipastoreo?).

b. Camélidos grandes en actitud de carrera (icaza?).

c. Ave con alas extendidas

\section{- Diseños varios:}

a. Líquido en movimiento o "serpiente".

b. Cuchillo / tumi o "bote".

c. Diseños sin definir.

La simple observación indica que el tema de mayor importancia expresado en las pictografías de Tupinachaca está referido a la caza o pastoreo de camélidos. Probablemente se trate de llamas, alpacas y vicuñas, animales que desde tiempos prehispánicos son parte importante de la economía y subsistencia de los pobladores de las cabeceras de los valles de la costa central. 
Según algunos de nuestros entrevistados, a tres horas al este de Tupe, en la zona denominada Porochik, camino hacia el departamento de Huancayo, ya es posible encontrar llamas (Lama glama glama), alpacas (Auchenia pacus) y probablemente guanacos (Lama glama guanicoe).

José Matos Mar (1951: 45) hace referencia a la ganadería de camélidos en la puna cercana a Tupe, y menciona que además de las especies "puras", existe diversos cruces como las crías de alpacas y vicuñas (Vicugna vicugna), y el mishte que es el cruce de llamas y alpacas. Lamentablemente desde la introducción española de ovinos, caprinos y vacunos, la crianza de camélidos ha disminuido dramáticamente en comparación con tiempos antiguos.

Hay que recordar que estas nacientes de valles eran la principal puerta de acceso de las caravanas procedentes de la puna y de la misma Hoya del Mantaro, las cuales se trasladaban hasta el litoral en busca de productos de intercambio. Este movimiento comercial fue una de las actividades más beneficiosas del señorío de los yauyos, quienes sirvieron de nexo entre ambos extremos de la red comercial puna-costa, como mencionamos párrafos atrás.

Asimismo los camélidos son un importante elemento de los rituales propiciatorios de nuestras serranías desde épocas inmemoriales. El sacrificio de llamas es registrado desde las primeras crónicas y en Tupinachaca eran ofrecidos para solicitar buenas siembras incluso en el siglo XX, como lo comenta Carmen Delgado de Thays (1959: 274). iSerá este el motivo por lo cual hay un cuchillo o tumi entre las pictografías?

Mario Polia (1999: 114) señala que los camélidos se ofrecían como "sacrificios mayores" y según los cronistas se preferían los albinos. Añade que Cristóbal de Molina los llama Barcapaña y eran animales ofrecidos al Sol, mientras Santa Cruz Pachacuti Yamqui denomina arpay al camélido blanco a sacrificar. Otro detalle importante registrado por
Polia (1999: 115) es el uso del sebo de llamas o wira para ciertas actividades rituales.

Los diseños de camélidos, cuchillos y "probables oficiantes" se encuentran en el Apu de Tupe, principal benefactor, intermediario y protector de la comunidad. Esto nos lleva a pensar que es muy probable que en este lugar se hayan realizado rituales además de enterramientos durante la época prehispánica.

Tupinachaca integraría junto al Pariaqaca y el ídolo Wallallo el panteón de divinidades más importantes de los yauyos precolombinos. Lamentablemente no contamos con una descripción precisa de la forma o las formas cómo se materializaban en el inconsciente de la gente estas deidades, pero sería sugeren-



Figura 13. Altar lítico con 5 orificios. 
te pensar que la diferenciación de tamaños y atributos entre los personajes antropomorfos de las pictografías quizás estén definiendo a las deidades o en todo caso a personajes de elite como señores u oficiantes (grandes personajes antropomorfos con tocado y unku; asexuados) y a los hombres comunes dedicados al pastoreo o la caza de camélidos (pequeños personajes antropomorfos de sexo masculino).

\section{Sector III. Altar lítico}

Esta es una gran piedra en las cercanías de las estructuras funerarias descritas, $100 \mathrm{~m}$ al este del farallón de las pictografías, prácticamente en las orillas del acantilado que da forma a la ladera sur del Tupinachaca. Julio C. Tello (1929: 37) es el primero en mencionar esta "roca excavada". Se trata de una gran laja plana que mide $3 \times 2 \mathrm{~m}$ aproximadamente, y tiene labradas cinco depresiones circulares de poca profundidad, formando casi una línea recta. Cada una de estas concavidades tiene un promedio de $50 \mathrm{~cm}$ de diámetro y están separadas entre sí por una distancia menor a $10 \mathrm{~cm}$. (Fig. 13)

Este tipo de piedras con depresiones circulares no son raras en la arqueología andina; están presentes desde el período Formativo (1500 -100 a.C.) hasta la época Inca. Sitios tempranos como Chavín de Huantar (Altar de Choque Chinchay o de "Las siete cabrillas") y Poro Poro (Altar de La Grada) presentan este tipo de cavidades que han sido asociadas generalmente a rituales vinculados con las lluvias y la fertilidad o a la observación astronómica mediante su uso como espejos de agua, los cuales reflejarían posiciones de estrellas en un tiempo determinado quizás referente al inicio o fin de las lluvias (Del Carpio, Mac Kay y Santa Cruz, 2001: 110-111)

En el caso de la piedra observada en Tupinachaca, nos arriesgaríamos a afirmar, a partir de las características de los sitios ya mencionados y la presencia de cerámica negra aparentemente formativa ("chavinoide") vista por Tello en la década de 1920 (Tello 1929: 98), que esta piedra o altar lítico correspondería a una ocupación anterior al tiempo de los yauyos, y más bien sería una evidencia concreta del período formativo, muy probablemente de las fases media a tardía (1000 - 600 a.C.).

\section{TUPINACHACA Y LOS ANTIGUOS YAUYOS}

De acuerdo a lo observado, consideramos al sitio arqueológico de Tupinachaca como el de mayor importancia política e ideológica en el área circundante a Tupe y quizás a toda la cabecera del río Cañete. Este sitio debió ser el asentamiento original de los pobladores yauyos hablantes del jaqaru, pero al igual que cientos de pueblos de la serranía peruana fueron obligados a trasladarse a zonas más bajas y más accesibles para su control y evangelización por parte de las autoridades políticas y eclesiásticas españolas. Prueba de ello es la construcción de la iglesia de Tupe a fines del siglo XVIII.

Es interesante recordar que el santo patrón más importante del actual poblado de Tupe es san Bartolomé apóstol (recordemos el nombre original del pueblo) quien, junto a los apóstoles Tomás y Santiago y el propio Jesucristo, fueron asociados en tiempos de la conquista con Tunupa Wiraqocha e Illapa (el trueno o rayo), deidades supremas en gran parte de los Andes, pero sobre todo de la región altiplánica o aymara (Polia 1999: 85). Gregorio García (Valcárcel 1985: 107) y el autor anónimo de la Relación de las costumbres antiguas de los naturales del Perú (Jesuita anónimo 1992: 58) detallan esta supuesta relación entre el apóstol Bartolomé y Tunupa. Esta simbiosis se debe aparentemente a similitudes de cierta imagen del dios Wiraqocha que se encontraba en el Templo del Sol con la caracterización hispana del apóstol y sus conocidos viajes de evangelización a tierras lejanas como Persia, India y Armenia, lugar de su martirio y muerte.

Quizás sería importante observar con detenimiento algunos aspectos de la iglesia de Tupe, 
estructura construida al parecer entre los siglos XVII y XVIII luego de la llegada de los primeros frailes dominicos a la zona (Matos Mar 1956: 5). Es probable que algunos detalles de la planificación (orientación y ubicación de accesos) y ornamentación (iconos o imágenes) de este templo nos puedan revelar más acerca de este sincretismo entre deidades, característica del Perú colonial durante los procesos de evangelización y extirpación de idolatrías.

Se suma a esto la segunda imagen más reverenciada por los tupinos: la virgen de la Candelaria, advocación de la virgen María que tiene su origen y mayor devoción en el departamento de Puno, territorio de población mayoritariamente aymara. Ello refuerza las teorías de los nexos culturales entre el pueblo de Tupe, su origen yauyo y la cultura aymara camuflada en un sincretismo religioso muy discreto.

Según lo observado durante nuestra visita, el Tupinachaca debió ser el hogar de los antiguos yauyos asentados en la cabecera del río Cañete, pero además sirvió de cementerio y lugar de diversas prácticas religiosas como lo evidencian las estructuras funerarias al interior de abrigos rocosos. La gran roca con las concavidades circulares y los artefactos recuperados en los trabajos de Tello, destacan la importancia del Tupinachaca como lugar de culto desde el Período Formativo.

Es muy probable que los pobladores del Tupinachaca hayan sido parte de la gran masa campesina de agricultores y pastores de la zona, y es quizás el sitio de Campana-Torre o Cambanduri (a unas 4 horas al este de Tupe, frente al actual poblado de Aiza), el lugar que habitaron las clases dirigentes. Campana-Torre es la gran elevación natural frente a Aiza, el anexo más importante de Tupe y donde también se con serva aún las tradiciones de la vestimenta tradicional (cotidiana) y la lengua jaqaru.

Si bien no fue posible visitar este lugar, pudimos observar durante la ruta Tupe-Aiza, la presencia de chullpas y estructuras arquitectónicas más sofisticadas que en Tupinachaca. Según los pobladores, en Campana-Torre la arquitectura es más fina y "tiene barro" entre las piedras. Como hemos afirmado, en Tupinachaca no hay evidencias de mortero o argamasa entre las piedras; además el uso de chullpas en las cabeceras de los valles costeños en tiempos tardíos es también registrado por Villar Córdova como una de las pruebas de la expansión de los yauyos. Estas chullpas eran estructuras funerarias de mayor rango y dimensiones que las "mastabas" o cistas, además de ser un elemento típico de las etnias aymaras desde la sierra limeña hasta el Altiplano peruano-boliviano.

Puede parecer una contradicción postular al Apu Tupinachaca frente a Campana-Torre como lugar de la elite. Esto podría aclararse por la situación estratégica de Campana-Torre, en una elevación menor que el Tupinachaca pero



Figura 14. Señora Angélica Casas vestida con el anako. 


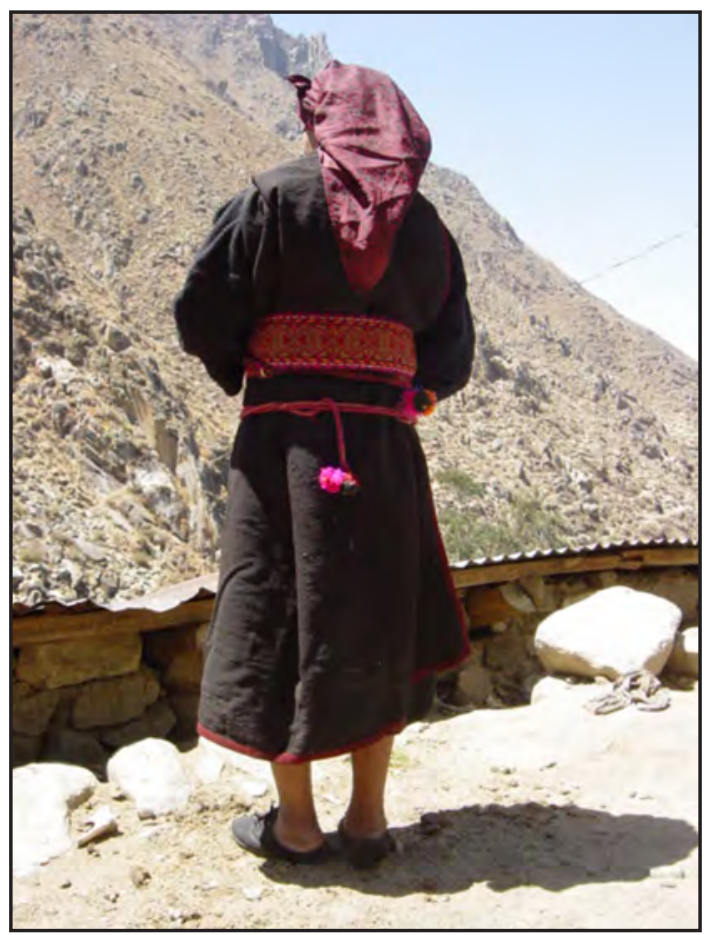

Figura 15.Vista posterior.

más escarpada y protegida, además de visualizar desde él gran parte del valle alto y medio de Cañete, lo cual incluye la observación de cientos de andenes agrícolas prehispánicos que continúan en uso. Sería pues un lugar idóneo para el control del territorio por parte de la dirigencia. En cambio, Tupinachaca sería el lugar sagrado en donde los yauyos se identificarían con su lugar de origen, sus dioses y sus propios ancestros.

Tupinachaca sería pues el Apu, vivienda de vivos y muertos, guardián de las cosechas y probablemente observatorio y oráculo del clima venidero. Recordemos que un Apu, en el caso de cerro o rocas, está relacionado con el concepto de huaca (objeto o lugar sagrado) y se relacionan con los héroes culturales, los lugares de origen o pacarinas y el origen de las aguas (Polia 1999: 182-183). Esta idea encuentra refuerzo en la traducción que el señor Isidoro Iturrizaga dio a la palabra "Tupinachaca" en 1941: "abuelo defensor" (Matos 1956: 6).
Tupinachaca y otros sitios arqueológicos de la zona podrían ayudarnos a reconstruir junto con las fuentes etnohistóricas, la vida de la antigua sociedad de los yauyos y sus antecesores que, en cierta manera, se han perpetuado en el actual poblado de Tupe.

\section{LA VESTIMENTA TRADICIONAL EN TUPE}

Una de las peculiaridades de Tupe es la vestimenta que llevan sus mujeres, quienes han conservado su vestuario tradicional hasta nuestros días con muy pocos cambios. Ellas utilizan dos tipos distintos de vestido:

\section{Vestimenta típica (Fig. 14 y Fig. 15)}

Cuando las mujeres lucen este tipo de vestido, se colocan en la cabeza un pañuelo de color rojo o negro que se amarra de diferentes formas. Este pañuelo es generalmente de seda o alguna tela similar y se trae desde Lima. El tocado se

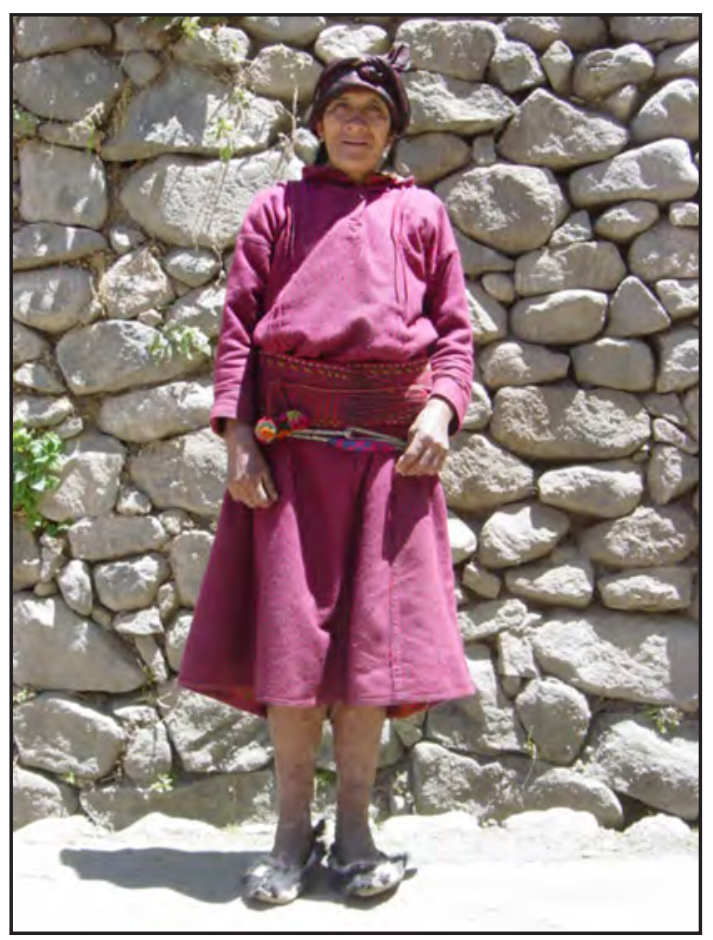

Figura 16. Señora Delia Acevedo vestida con el tartán $y$ calzando shucuy. 
complementa colocando pompones o borlas en las trenzas.

Inmediatamente sobre el cuerpo se coloca el coton o camisón negro. Sobre éste visten el anako, especie de mandil o delantal negro con ribetes rojos, confeccionado con lana de alpaca en el mismo Tupe. En la espalda llevan una manta de color negro con algunas franjas mayormente de tonos rojos, que es agarrada de forma cruzada por los tupus a la altura del pecho, como se puede apreciar en las fotos de Rosalía Ávalos de Matos (1952) y Carmen Delgado de Thays (1959); también es confeccionada en Tupe.

Sobre el anako va la faja interna o marate, hecha de lana y champacara (hoja de maguey); ella sujeta la faja y la pone firme. Esta última es hecha con lana de vicuña, puede ser de color marrón o rojo. Debajo de la faja, a la altura de la cadera, se coloca la huaraca o cintas de lana con los pompones o borlas.

En el pecho, colgando desde el cuello, lucen el piñe o adorno de antiguas monedas de

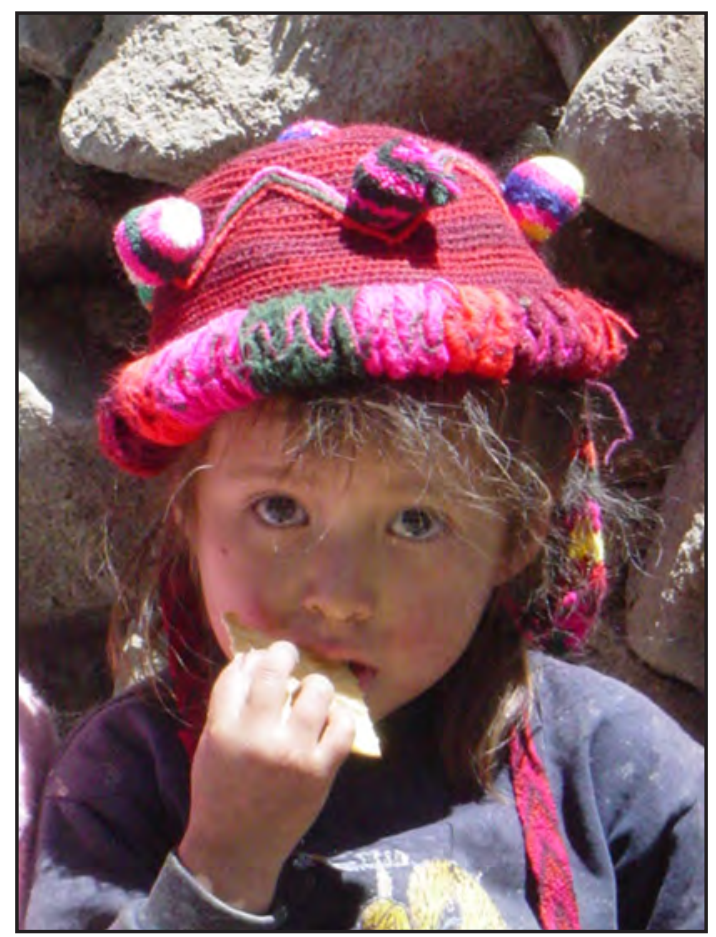

Figura 17. Niña menor de 6 años usando el característico gorro tejido.

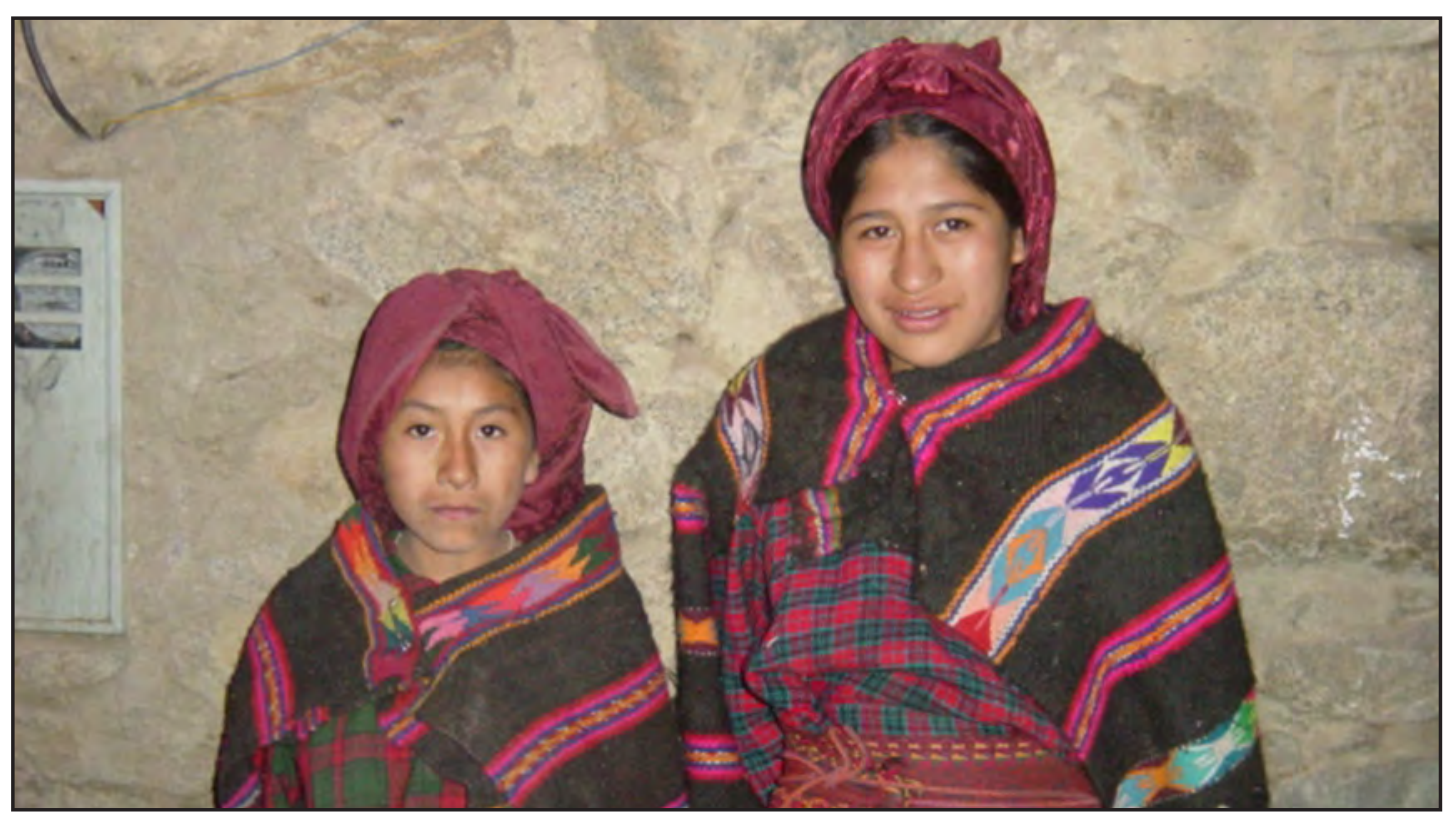

Figura 18. Niñas vistiendo el tartán con la manta o lliclla para abrigarse. Nótese que se usa el prendedor o "imperdible" para sujetar la manta. 


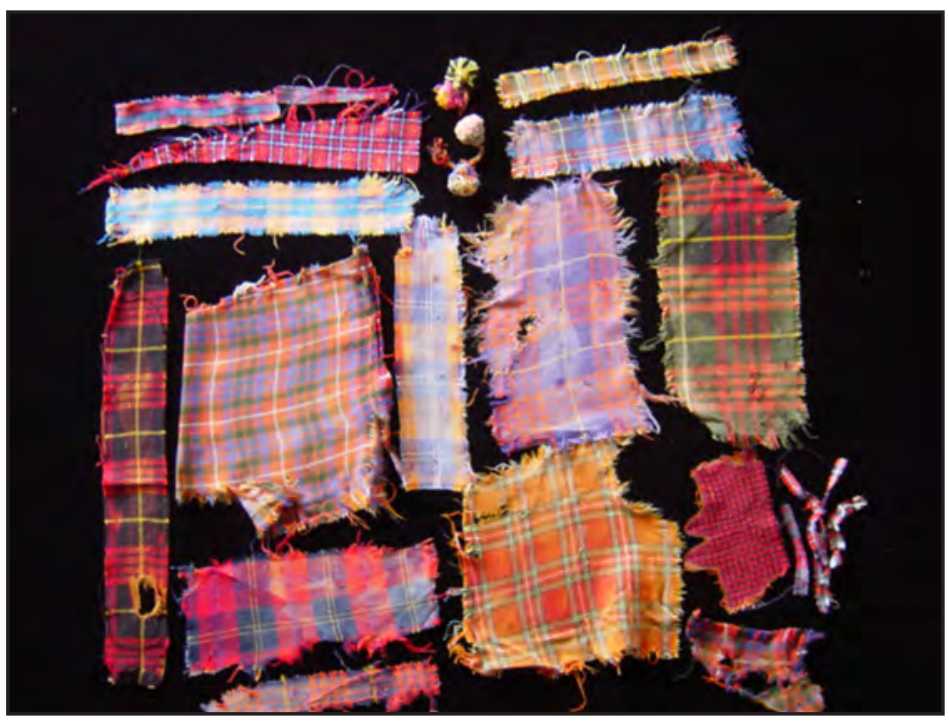

Figura 19. Restos de telas utilizadas para confeccionar el vestido cotidiano o tartán.

plata; algunas tienen fechas entre 1850 y 1980 . En las orejas se colocaban los aretes denominados "tres caídas"; compuestos también por monedas de plata que cuelgan una tras otra. El calzado se denomina shucuy y se hace con cuero de vaca en el mismo pueblo.

\section{VeSTIMENTA COTIDIANA (FIG. 16)}

El tocado es el mismo que se usa con el atuendo descrito anteriormente.

Sobre el cuerpo se viste el camisón a cuadros que llamaremos tartán ${ }^{2}$; éste se confecciona con telas de algodón o franela en distintas tonalidades de rojo, que son llevadas desde Lima. La manta es la misma que la del atuendo anterior, se coloca de manera similar y se agarra con un prendedor ("imperdible"), en lugar de los tupus. Los otros complementos (marate, faja y huaraca) son los mismos que aquellos de la vestimenta descrita y se usan de la misma manera, al igual que el calzado o shucuy. Una diferencia evidente es el uso de llaves pequeñas colgantes (idel candado de la casa?) en lugar del piñe; tampoco se usan los aretes "tres caídas".

Las niñas usan un "gorro" tejido (Fig. 17) hasta los 5 años; un año después ya visten el traje de diario o tartán, la faja y la manta para abrigarse (Fig. 18). El tocado es principalmente utilitario pues sopor- ta la cuerda que ciñe la frente y cae por la espalda y sujeta un peso de hasta 100 kilos según nuestros informantes.

Los hombres visten pantalón, faja, sombrero de paño y calzan los shucuy. La camisa tiene cuadros pequeños. Según las descripciones de Delgado de Thays (1959) y Hardman (1983), los hombres usaban también el poncho; durante nuestra estadía hemos visto que éste ha sido reemplazado por la chompa o pullover.

A lo largo del camino hacia Tupe, encontramos en el suelo restos de telas con las que seguramente fueron confeccionados los vestidos de diario o tartán (Fig. 19). Estas telas escocesas son de varios colores, destacando el rojo. Pero al llegar a Aiza y luego a Tupe, nos extrañó ver que la gente no usaba telas con estos diseños (cuadrados) y colores, sino más bien se habían limitado a cuadrados pequeños de tonos rojo y negro; en muy pocos casos se observó el rojo con cuadrados grandes de color verde o el rojo combinado con el azul. Pensamos en un primer momento que la diferencia en cuanto al diseño del tartán o vestido de diario podría corresponder a la representación de distintos ayllus o clanes como era costumbre en

2 Los distintos patrones de vestimenta son conocidos como tartán. Esta palabra parece tener un origen europeo, alrededor del siglo XV, y es utilizada para distinguir los diferentes clanes y la territorialidad de los mismos en base a la combinación de colores utilizada en la tela con la cual se confeccionaría la prenda de vestir (Mac Kay 2000). 


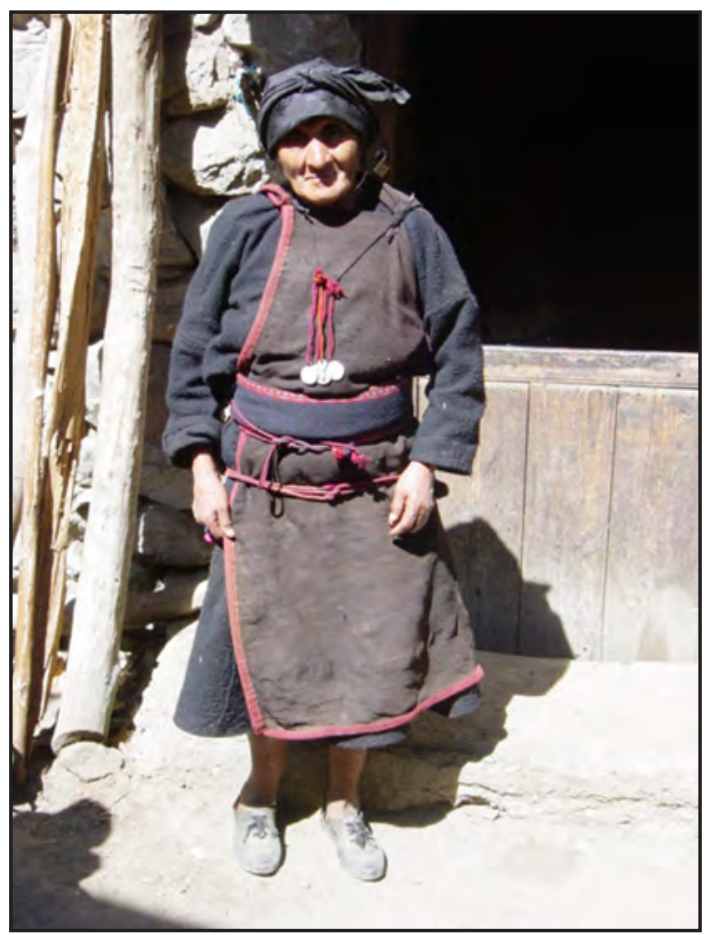

Figura 20. Señora Alcisa Cuevas vistiendo de luto con el pañuelo negro y el anako.

Escocia en el siglo XVI (Mac Kay 2000), pero los pobladores afirmaron que cada persona elegía la tela para su vestido.

Tello y Mejía Xesspe (1979:10) describen con detalle la vestimenta típica de la mujer tupina: "Es interesante contemplar a las mujeres, durante las reuniones sociales o días festivos, muy ataviadas uniformemente, de pies a cabeza con Shuke, shukuy u ojota, con correaje multicolor, con urko o faldellín de lana negra que ciñe al busto, con katra o kat-ra, especie de lliklla o manta de lana negra con tokapo o banda marginal polícromo, que cubre el dorso graciosamente prendida en el pecho con tupu o alfiler de plata, y finalmente, la cabeza con un tocado rojo, a la manera de wincha o diadema, que recuerda la primitiva ñañaka de las ñustas del Cusco".

En la década de 1950, Delgado de Tahys (1959) y Hardman (1983) observaron a las mujeres vestirse con el anako y los tupus. Como describe Hardman: "Las mujeres todavía se visten con la indumentaria típica, la cual contrasta marcadamente con las demás vestimentas indígenas del Perú. Es un vestido recto de lana negra de alpaca tejido a mano, ribeteado con un tejido angosto de color oscuro y sostenido en los hombros con dos grandes prendedores de plata llamados 'topos' en castellano... Es una vestimenta muy llamativa y bastante cara. El tejido, quizás el más fino en el Perú actual, demora casi un año en confeccionarse... Las jóvenes tienen que ponerse el vestido costeño o mestizo (tartán), de franela de algodón, hasta que puedan comprar la muy estimada indumentaria nativa." (1983: 25-26).

La señora Alcisa Cuevas Flores empezó a usar el anako a los 30 años; ella heredó de su madre (quien a su vez los había heredado de su abuela) el piñe, los aretes y los tupus de plata que aún continúa usando. Al momento de nuestra visita, se encontraba de luto por la muerte de un hermano; y por ello vestía el anako y pañue-

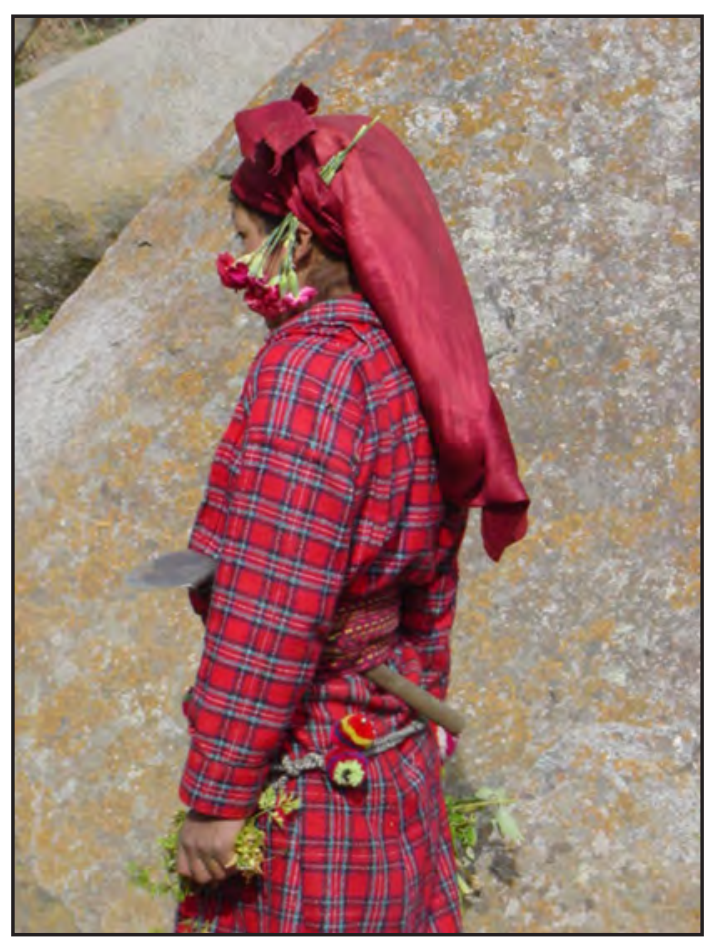

Figura 21. Niña vistiendo el tartán y adornándose la cabeza con un ramillete de flores del campo. 
lo de luto (de color negro) durante un año, y no llevaba los tupus ni los aretes (Fig. 20). Nos contó con pena que años atrás, las jóvenes de 20 a 25 años empezaban a usar el anako, dejando de lado el traje a cuadritos o tartán, pero que esa costumbre se está perdiendo. Es muy posible que una de las razones sea el costo que implica conservar los tupus, el piñe y el anako, como lo menciona Hardman, aunque también es muy complicado colocarse el anako y demora un tiempo considerable. Esto lo comprobamos al esperar 30 minutos a que la señora Angélica Casas se vistiese con el anako, con ayuda de su hija Mariella Iturrizaga (profesora de secundaria del colegio de Tupe), para tomarle algunas fotos.

Aunque ni Tello y Mejía Xesspe (1979), ni Hardman (1983) mencionan ningún tipo de sombrero como parte de la vestimenta de la mujer tupina, Ávalos de Matos (1952) y Delgado de Thays (1959) presentan fotografías de las mujeres usando un sombrero de paño adornado con flores, y vistiendo el anako y la manta con los tupus cruzados. Quizás este sombrero reemplazaba al pañuelo en momentos importantes como son las fiestas de los santos patronos. Nosotros no pudimos comprobar el uso de este sombrero actualmente, tampoco fue mencionado por nuestros informantes como parte de la vestimenta de la mujer tupina; aunque pudimos ver a algunas niñas colocarse flores detrás de la oreja como adorno (Fig. 21). Es probable que el uso de este sombrero se haya perdido, como está sucediendo con otras partes del atuendo de las mujeres y los varones.

Es interesante destacar que las descripciones de Tello y Mejía Xesspe se basan en las observaciones de Tello durante su visita a Tupe en 1926, mientras que Ávalos de Matos, Hardman y Delgado de Thays visitaron el pueblo en la dé- cada de 1950. En el lapso de casi 30 años no se observan diferencias en el uso de la vestimenta nativa; en cambio, 50 años más tarde, durante nuestra visita realizada en noviembre del 2003, pudimos comprobar la pérdida progresiva del uso de esta bella vestimenta femenina. Algunas de las causas posibles fueron mencionadas líneas arriba.

Un comentario de Ávalos de Matos y Delgado de Thays que creemos interesante mencionar es que la confección o tejido del anako, ponchos, mantas de diario o katras, mantas de fiesta o milakatras; forma parte de las tareas masculinas, mientras que la confección del marate es compartida con las mujeres. Según Ávalos (1952:42-43): "La razón por la que las mujeres dicen no tejer ponchos, 'anacos', ni mantas, es que el telar es muy ancho y no les da el brazo". Se suele afirmar que en el territorio andino la actividad textil ha estado restringida al ámbito femenino, por lo que resulta poco común que este tipo de tarea la realicen los hombres.

\section{Los TUPUS}

Los tupus son prendedores usados como parte de la vestimenta femenina en el Perú prehispánico (Vetter 2004, 2007). Muchas veces ha sido asociado con los incas, pero su uso se remonta alrededor de 1000 años antes, con los mochicas, tal como lo ilustra una vasija del Museo Etnológico de Berlín, que corresponde a la fase Moche IV (alrededor de 400 años d.C.) $)^{3}$. En ésta hemos podido observar que la forma de los tupus no es circular, como comúnmente se les conoce, sino más bien es alargada, casi rectangular, con esquinas redondeadas. En un ceramio nazca tardío (de la colección del Museo Etnológico de Berlín, fase Nazca 7, entre 500 a 650 d.C.) se ha representado a una mujer hilando que tiene en cada uno de sus hombros un

3 Agradecemos a Anne Marie Hocquenghem haber compartido con nosotros las fotos de las vasijas moche y nazca que mencionamos en este párrafo. 


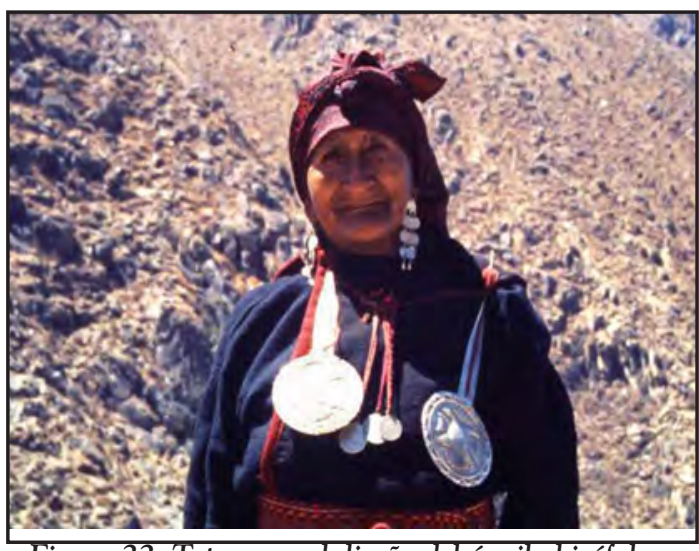

Figura 22. Tupus con el diseño del águila bicéfala y mostrando el piñe entre ellos.

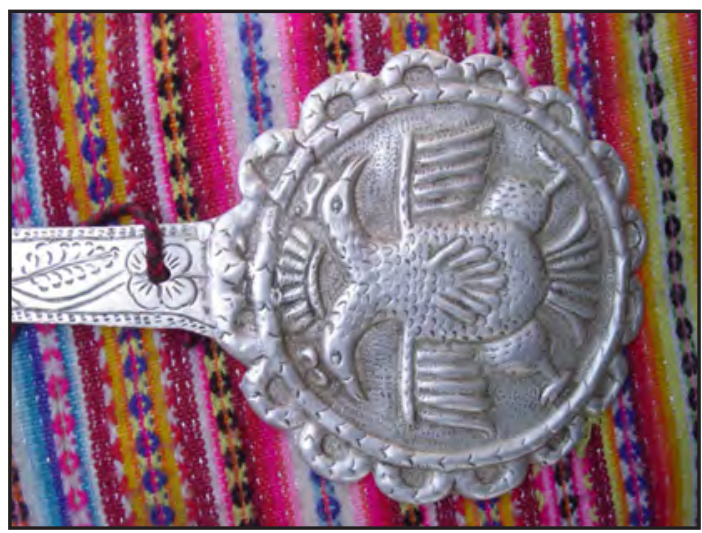

Figura 23. Tupu con la decoración del águila bicéfala hecha con la técnica del repujado.

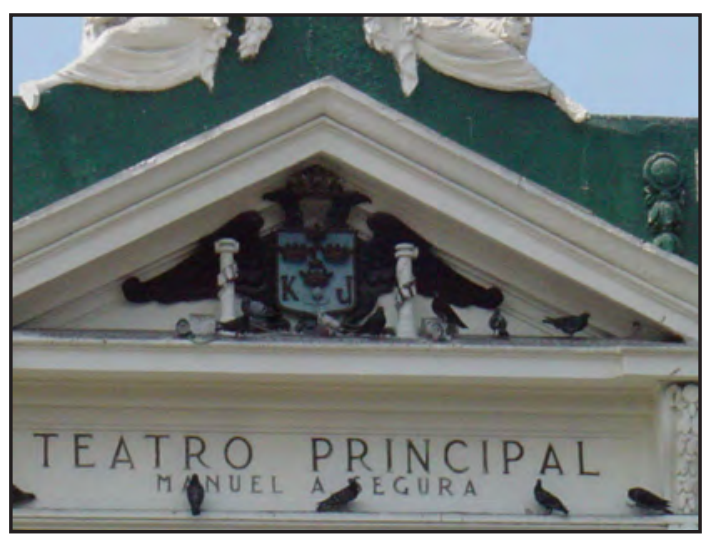

Figura 24. Escudo de Carlos V de Alemania o I de España en el teatro Segura de Lima, antiguo teatro Principal, creado en el Virreinato.

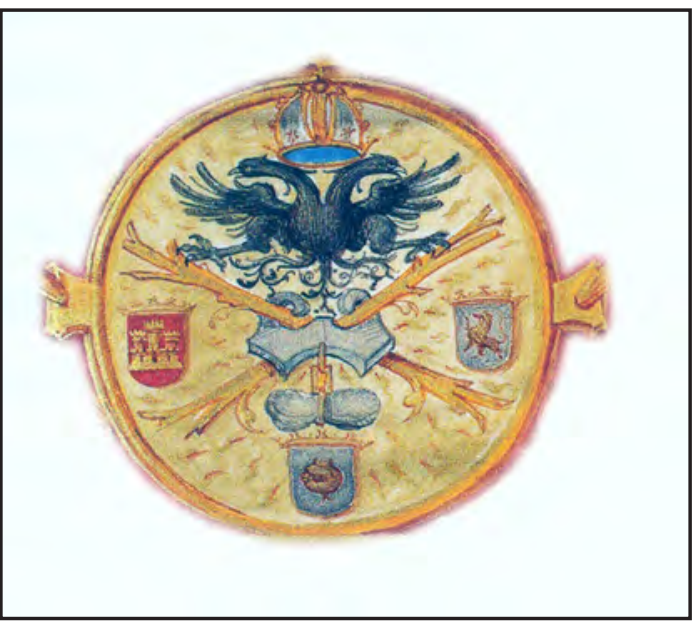

Figura 25. Escudo de Carlos V de Alemania y I de España. Tomado del Catálogo de la exposición "Carolus", editado por la Sociedad Estatal para la Acción Cultural Exterior S.A. Madrid, ctubre de 2000. tupu, cuya forma es similar a aquella mencionada para la vasija mochica.

En algunas piezas del Horizonte Medio, cultura Huari, se han registrado tupus de cabeza circular es posible que esta forma haya existido anteriormente- y continúan apareciendo en el Intermedio Tardío (Chancay) y después con los incas. La iconografía representada en los tupus es limitada, en algunos casos se puede observar figuras geométricas incisas o repujadas, pero muy simples. Sin embargo, existen tupus hechos en moldes y con diferentes figuras antropomorfas, fitomorfas, geométricas, etc.

Durante la Colonia, la iconografía se complejiza y podemos observar personajes, escenas, y el uso de dijes que representan el sincretismo entre lo andino y lo español (como en algunas piezas del Museo Pedro de Osma, en Lima). Los tupus se elaboran solamente en plata, a diferencia de la época prehispánica, cuando eran confeccionados en cobre, bronce, plata u oro. Recordemos que el descubrimiento y posterior explotación de la mina de Potosí dio origen al auge de la platería. A partir del establecimiento de la República, el uso del tupu varió. La aguja ya no se colocaba de forma diagonal, sino ho- 
rizontal, como los prendedores españoles. Más tarde perderán la aguja larga y sólo tendrán una pequeña, imperceptible a la vista, que hará las veces de gancho.

En el periodo colonial el tupu adquiere como elemento nuevo la incrustación de cuentas de vidrio como parte de la decoración. Este rasgo se conservará durante la República, así también se continuarán usando los dijes o colgantes que mencionamos líneas arriba, los cuales los harán más llamativos, además de producir cierto sonido al caminar.

Los tupus que utilizan las mujeres de Tupe son circulares y su forma se asemeja a la de sus pares coloniales. En ellos se observan elementos iconográficos que simbolizan el sincretismo entre los poderes políticos prehispánicos y del Viejo Mundo. (Fig. 22)

En el tupu de la Figura 23 observamos en la parte de la circunferencia un águila bicéfala, elaborada en forma repujada. Ella nos recuerda el escudo familiar de los Habsburgo, específicamente aquel de Carlos V de Alemania y I de España, monarca español al momento de la conquista del Perú en el siglo XVI por Francisco Pizarro. (Fig. 24 y 25). Los dos pares de tupus que conseguimos nos mostraran tenían la misma decoración.

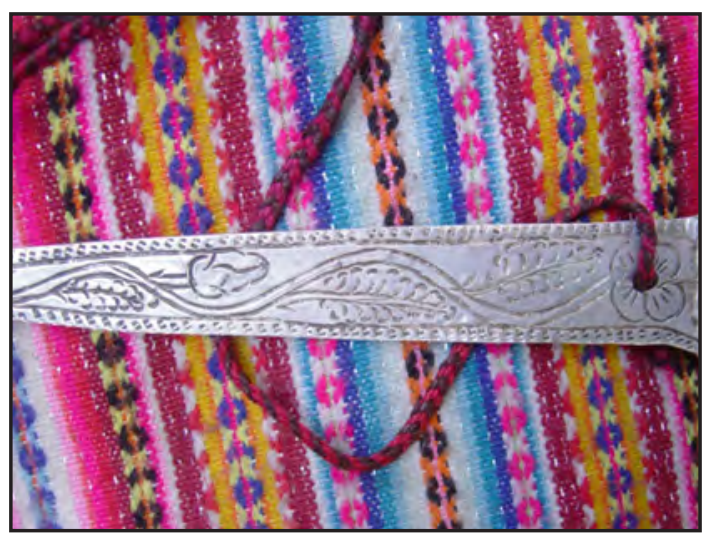

Figura 26. Sección de la aguja del tupu decorada con incisiones que representan una rama principal con hojas pequeñas y una flor.
En 1537, la corona española otorga a la ciudad de Lima un escudo de armas el cual es una modificación del escudo personal de Carlos V, en donde las águilas bicéfalas Habsburgo pasan a ser dos águilas que se observan mutuamente (Del Busto, 1994:194).

Flores Ochoa y otros (1998) mencionan la similitud que puede tener el águila bicéfala de los Habsburgo con la que aparece en la heráldica colonial de los curacas y coyas, como por ejemplo en el escudo de armas de la puerta principal del palacio de la coya Cusi Chimbo. En algunos de los keros que analizan dichos autores se observa al águila bicéfala debajo del arco iris, lo cual se relacionaría a su vez con la descripción que hace Santa Cruz Pachacuti del cerro Huanacaure que es el Apu principal de la etnia inca.

Es evidente que el águila bicéfala se relaciona con la representación del símbolo del poder político en el mundo andino. Probablemente esta imagen fue un medio para integrar a los curacas, lideres o nobleza nativa a la organización de poder virreinal desde el siglo XVI, como lo mencionan Flores Ochoa y otros (1998). Es importante observar que no todos los tupus que conocemos de Tupe llevan este diseño, quizás porque se trate de un "tipo" de tupu para gente especial, lo que podría indicar la importancia política de la persona que los use. Es posible que estos los identificaran como miembros de algún grupo de poder político o como pertenecientes a un grupo étnico de prestigio (idescendientes de los curacas yauyos?). Una alternativa es que en la historia familiar de las señoras que nos mostraron sus tupus haya habido algún caso de relación con el poder, pues hay que recordar que estos tupus son heredados de generación en generación, lo que favorece la idea de la antigüedad de los diseños.

Otro elemento iconográfico que se observa en los tupus (Velarde 2002) es el escudo nacional, cuyo diseño corresponde a mediados del siglo XIX, y ha sido elaborado con la técnica de 


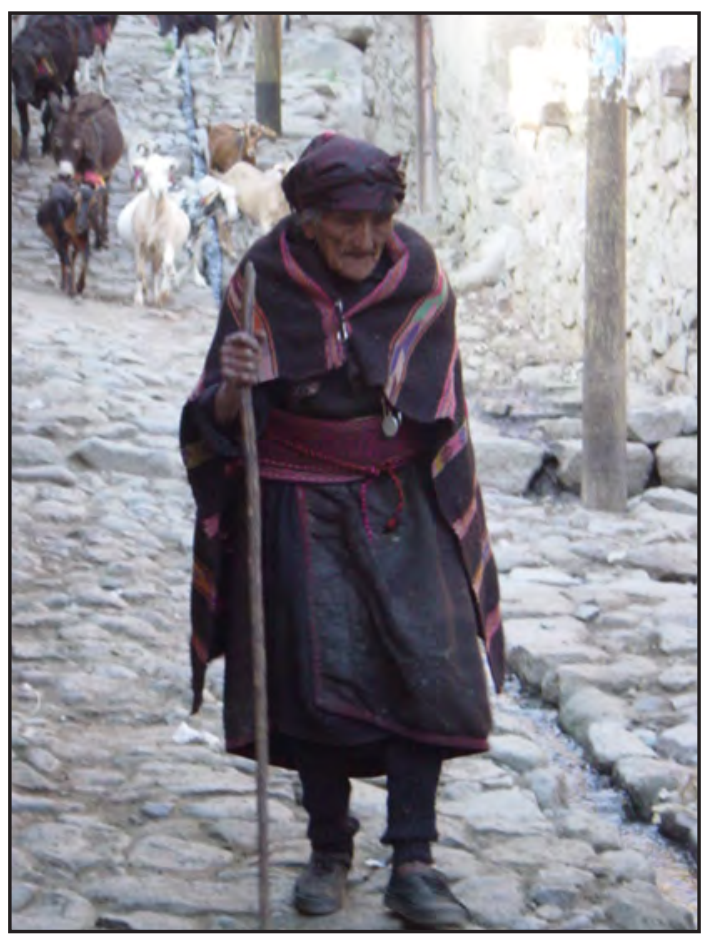

Figura 27. Señora tupina vestida con el anako y la manta o lliclla, pero en vez de usar los tupus para sujetar la manta, se ha colocado un prendedor o "imperdible".

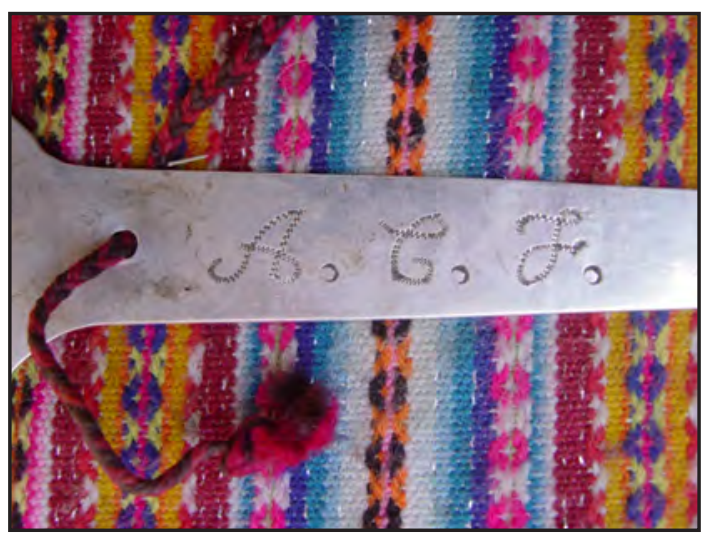

Figura 28. Señora tupina vestida con el anako y la manta o lliclla, pero en vez de usar los tupus para sujetar la manta, se ha colocado un prendedor o "imperdible".

incisión. Es interesante notar que ambos diseños son símbolos que representan el poder político probablemente vigente al momento de la manufactura de los tupus.
Si bien es tentador afirmar que los tupus que presentan como elemento iconográfico al águila bicéfala fueron confeccionados alrededor de los siglos XVI al XVIII (cuando los españoles estaban en pleno trabajo de evangelización), desconocemos el momento exacto en que fueron elaborados. Es muy probable que aquellos con el escudo nacional hayan sido elaborados a mediados de la República. Sin embargo, somos conscientes que éstas son inferencias muy subjetivas y por ello no las afirmamos.

Las figuras del águila bicéfala y el escudo nacional se encuentran en la circunferencia del tupu; en la aguja propiamente dicha se observan diseños incisos de flores y hojas. En el caso de los tupus de las señoras Casas y Cuevas, se observa una gran rama que sostiene desde el inicio de la punta hasta la unión de ésta con la zona de la circunferencia una serie de hojitas muy bien elaboradas. Al llegar a la unión entre la aguja y la circunferencia aparece una pequeña flor que señala el fin de la aguja. Estas incisiones son muy finas y muy bien trabajadas, se nota la mano de un especialista en su trazo (Fig. 26).

Los tupus se colocan en el anako a la altura del pecho, tal como lo ilustra Guamán Poma de Ayala (1993) en sus dibujos de la primera y novena coyas. Pero en las fotografías de Ávalos de Matos (1952) y Delgado de Thays (1959) se pueden ver a varias señoras usando el tupu de forma cruzada en el pecho, es decir, cruzando las puntas del tupu a la altura de la mitad del pecho, colocando la parte decorada (circunferencia) hacia arriba. En este caso, los tupus estarían sujetando la manta no el anako. En cambio, en las ilustraciones de Guamán Poma de Ayala (cuando se trata de dos tupus usados a la vez) y en nuestras observaciones in situ, vemos que los tupus se colocan uno a cada lado, a la altura del pecho, pero con la parte decorada (circunferencia) hacia abajo. En este caso, las puntas de la aguja sujetan la parte del anako que se encuentra en los hombros, de tal mane- 
ra que unen la sección trasera y delantera del mismo; de esta forma el anako no se mueve de su lugar. Imaginamos que las señoras deben estar acostumbradas a no pincharse con la aguja, ya que su punta queda expuesta a la altura de los hombros. Debemos mencionar que los tupus de Tupe destacan particularmente por su gran tamaño pues miden $25 \mathrm{cms}$ aproximadamente. No tuvimos la oportunidad de ver a ninguna señora que vistiera el anako con la manta y que ésta estuviera sujeta con los tupus, más bien, estaba sujeta por medio de un prendedor ("imperdible”). (Fig. 27)

Tanto en el caso de los tupus cruzados como en aquellos que van a cada lado de los hombros, se puede observar un cordel (quizás de lana de camélido) que los sujeta. Este cordel es de color rojo, y pasa por un agujero que se encuentra entre la aguja y la circunferencia o zona decorada. En el caso de los tupus fotografiados (en los que se puede observar este detalle con mayor precisión), se puede ver que el agujero ha sido perforado precisamente en el centro de la flor incisa, haciendo las veces del pistilo. Esto quiere decir que hubo un gran desempeño y cuidado del orfebre al elaborar cada pieza.

Uno de los pares de tupus que pudimos observar tenía inciso en el reverso las iniciales de la propietaria, señora Alcisa Cuevas Flores, en la zona de la aguja (Fig. 28). Si los tupus se heredan de generación en generación, entonces estas iniciales deben ser cambiadas al pasar de madre a hija.

Según cuentan las señoras de mayor edad, estos objetos fueron elaborados en Cañete o Lima; al parecer nunca fueron manufacturados en Tupe ni en ninguno de sus anexos. Las actividades principales de los tupinos son la agricultura y la ganadería, lo que no deja tiempo para dedicarse a otras actividades, como la orfebrería. Esta es una de las razones por las cuales el tupu resulta un elemento de lujo, que se hereda de madre a hija. Hardman (1983) menciona que existía en Lunahuaná un platero especialista en la manufactura de los tupus para la población de Tupe. Además, señala que estos objetos se han encontrado en las ruinas alrededor del pueblo, trabajados en cobre o bronce pero de menor tamaño.

Es importante destacar que, según los relatos de nuestros informantes, el mineral usado para la fabricación de estas piezas fue recogido en los alrededores de Tupe. Según la señora Angélica Casas: "en la bajada del río Tupe había cobre y plata, pero hace 12 años que no se explota. También arriba, en Huacracocha donde se podía extraer plata y oro". Ella afirmó también que su tío Abad Valerio decía: "estamos encima de minas". Es muy probable que se llevara el mineral de plata a Cañete o Lima para elaborar los tupus que serían usados por las mujeres. La señora Alcisa Cuevas comenta que "en el cerro de Miyococha había minas de cobre”.

Matos Mar (1956) recopiló la información existente sobre Yauyos, Tupe y el idioma Kauke desde el siglo XVI hasta esa fecha. Así nos enteramos que el corregidor de Yauyos, Diego Dávila Briceño, afirmaba que en el pueblo de San Bartolomé de Tupi (nombre con el que era conocido en el siglo XVI) tenía "muchas minas de plata en explotación”. Por su parte, Cosme Bueno (1764, citado por Matos Mar) menciona también que habían minas de plata y oro.

Antonio Raimondi (1939) recorrió los distritos actuales de Yauyos y Huarochirí, y describe varias minas donde se explotaba las vetas de minerales argentíferos y cupríferos. Hay que recordar que en el siglo XVI el territorio de la etnia Yauyos comprendía por el norte las actuales provincias limeñas de Huarochirí y parcialmente la de Canta, y por el sur un sector de la provincia de Castrovirreyna en el Departamento de Huancavelica; por lo tanto, las minas mencionadas por Raimondi en la provincia de Huarochirí pertenecían a esta etnia. Es muy posible que estas minas fueran trabaja- 


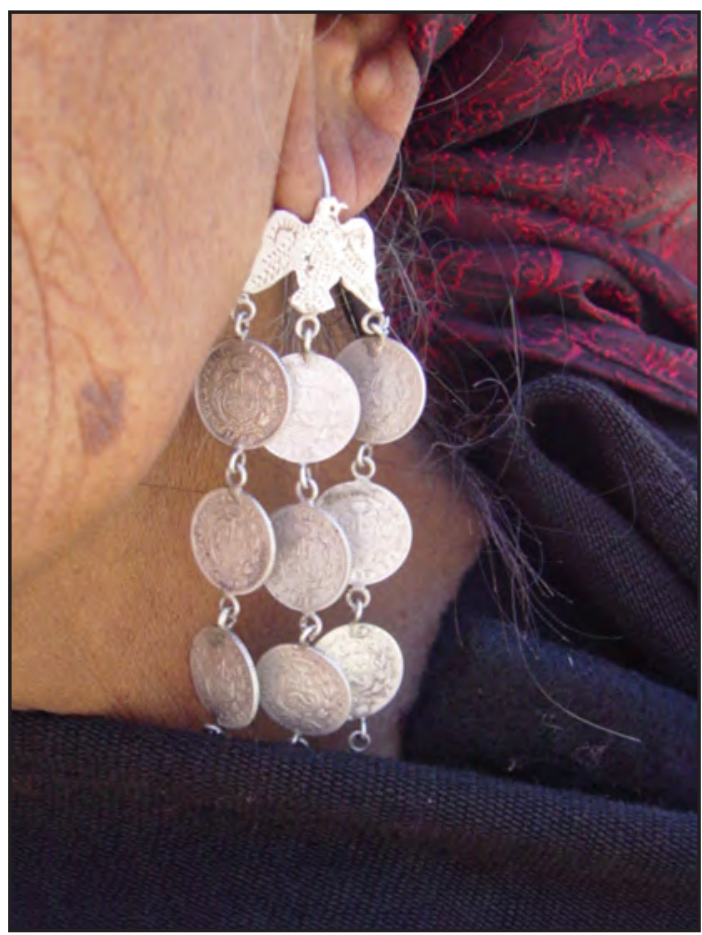

Figura 29. Aretes "tres caídas" elaborados con monedas de plata.

das en tiempos antiguos, dando lugar a la obtención del mineral de plata y minerales de cobre con los cuales se manufacturaron los tupus.

Así, los actuales distritos de la provincia de Huarochirí que Raimondi señala como poseedores de minas con explotación de menas de plata y cobre son: Carampoma (mina Canchiscancha, ubicada en Sacsacocha); Olleros (mina ubicada entre las quebradas de Lurín y Chilca, a la altura del pueblo de Olleros); San Mateo (minas Anticona, Calahuacta, de Santiago, Carlos Francisco, Yauliyaco, de Jirca, Conchupata y asiento minero de Parac, entre otras). Mientras que en el distrito de Tauripampa, de la actual provincia de Yauyos, las minas se encuentran cerca del pueblo de Picamarán.

Por otro lado, Salazar y Landa (1993) realizaron un estudio geológico de los cuadrángulos de Mala, Lunahuaná, Tupe, Conayca, Chincha, Tantará y Castrovirreyna, los que abarcan parte de los actuales departamentos de Lima (provincia de Cañete y Yauyos), Ica (provincia de Chincha), Huancavelica (provincias de Huancavelica-Castrovirreyna) y Junín (provincia de Huancayo). Esta zona se extiende desde el nivel del mar hasta las altas cumbres del flanco oriental de la Cordillera Occidental de los Andes. De esta manera se localizaron reservas de plomo, zinc, plata y algo de cobre, con evidencias de minas de producción en algunos de los cuadrángulos. Todo esto confirma las afirmaciones de los tupinos en relación a su ubicación en una zona minera.

Dada nuestra breve estadía en Tupe, no fue posible acceder a las minas que nuestros informantes mencionaron, ya que muchas de ellas quedaban a varias horas e inclusive días de distancia. Cabe mencionar que los ancianos afirman que en el río Tupe aún se puede encontrar evidencias de "oro" en las arenas fluviales, lo que no ha sido confirmado.

Algunas señoras comentaron que los tupus se fabricaban también derritiendo las antiguas monedas de plata. Para ello debieron haber tenido un excedente de estas monedas de plata, pues hay que tomar en cuenta que el piñe y los aretes de "tres caídas" se confeccionan con este tipo de monedas. Los tupus que hemos observado durante nuestra visita y en las fotografías de Ávalos de Matos, Delgado de Thays, y Velarde son piezas cuyo peso individual debe fluctuar entre los 200 y 250 grs. aproximadamente. Si se hicieron con monedas de plata antiguas, debió necesitarse alrededor de 12 a 15 monedas 4 para poder fabricar un par de tupus. Esta es una mera aproximación ya que hay que tener en cuenta que se desperdicia metal al cortar la lámina de metal para darle la forma del tupu. Si esto fue así, entonces podríamos pensar en un excedente económico, lo que contrasta fuertemente con lo que pudimos observar nosotros: una economía sólo de subsistencia. 


\section{EL PIÑE Y LOS ARETES “TRES CAÍDAS”}

El piñe es parte del adorno que llevan las mujeres junto con los tupus. Se coloca también a la altura del pecho y consiste en antiguas monedas de plata, que están sujetas por otro cordel (tal vez lana de camélido), también de color rojo, igual que el de los tupus. A su vez este cordel de lana se sujeta al cordel de los tupus, uniéndose un poco más arriba del pecho, formando de esta manera un solo conjunto (ver Fig. 22).

Este tipo de adorno es exclusivo de Tupe y lo usan sólo las señoras de mayor edad. En Aiza ya no los usan, simplemente se cuelgan unas llaves pequeñas (que pueden pertenecer al candado con el que cierran su casa) que hacen las veces de las monedas, respetando el cordel de lana y conservando el sonido característico del metal.

Los aretes "tres caídas" han dejado de usarse, incluso en Tupe; la señora Casas se los colocó exclusivamente para ser fotografiada (Fig. 29). Es posible que la desaparición de dichos objetos se deba a lo poco útil que resulta conservar las monedas de plata con un fin ornamental. Tal vez se haya preferido intercambiar los piñes o aretes de monedas de plata por ganado o semillas. La necesidad obliga a poner en segundo lugar los sentimientos y lo que simboliza un objeto que ha pertenecido a la familia por muchas generaciones.

\section{LA LENGUA JAQARU}

El jaqaru corresponde a la familia aru, de la cual se derivan el cauqui-aymara o jaqi de Martha Hardman (1983) y el cauqui o jaqaru, este último aún hablado por la población tupina. La palabra "jaqaru" se deriva de dos palabras: jaqi "gente" y aru "hablar".

Como señalan Matos Mar (1956) y Cerrón Palomino (1998), esta lengua no sólo captó la atención de los lingüistas, sino también de viajeros como Markham y Raimondi. En su momento, los padres de la arqueología peruana,
Tello (1929) y Uhle (Cerrón Palomino op. cit.) se interesaron también en ella.

Según Belleza Castro (citada por Torero 2002), el cauqui es hablado actualmente sólo en los pueblos de Tupe, Aiza, Colca, y Cachuy, entre otros; pero Martha Hardman (1983) cree que existen dos lenguas diferentes en el distrito de Tupe: el cauqui de Cachuy y el jaqaru o cauqui tupino de Tupe. Frente a esto, Torero (2002: 111) afirma que: "Nosotros hallamos que se trata, al menos hoy, de una sola lengua, pero que carga en sus muchos usos locales y puntuales una larga historia de interferencias y compromisos entre varios idiomas arus y entre idiomas arus e idiomas quechuas; todo esto agravado hoy por los truques y fluctuaciones fonológicos característicos de hablas que han perdido su vitalidad y van en creciente desuso (en este caso, ante el rápido avance del castellano)". Como mencionamos líneas arriba, los niños aprenden primero el castellano y cuando van a la escuela aprenden el jaqaru. Si a esto añadimos que el distrito de Tupe está rodeado de pueblos cuya lengua es el castellano o el quechua, es indudable una rápida extinción del jaqaru.

Es interesante precisar la evolución cronológica del protoaru que plantea Torero (2000, 2002). Hace siete u ocho milenios la forma cómo se dio el desarrollo del proceso de neolitización propició la diferencia lingüística en el territorio andino. Este proceso ocurrió de manera simultánea en muchos lugares del centro de los Andes, pero en aislamiento, lo que se explica por la necesidad de adaptarse a las difíciles condiciones fisiográficas y ecológicas andinas, en busca de mejores sitios para el proceso de domesticación de la flora y la fauna. Luego de tres mil años de este proceso de adaptación, se iniciaron los contactos entre los distintos grupos, logrando un intercambio mayor a principios de nuestra era. Como explica Torero, en el plano lingüístico, esta aproximación creciente favoreció a ciertos idiomas; alguno de ellos alcanzó nivel regional, 
desplazando o absorbiendo, en algunos casos, parte de los idiomas lugareños. Esto fue lo que sucedió con el protoquechua y el protoaru, cuyos lugares de origen estuvieron situados a una distancia relativamente cercana, en el centro de la costa peruana (el protoquechua) y en el sur de la costa peruana (el protoaru).

A fines del Intermedio Temprano e inicios del Horizonte Medio (entre 500 a 600 d.C.), el protoquechua ocupaba los departamentos actuales de Ancash, Huánuco, Pasco, Junín y Lima; mientras que el protoaru habría ocupado los de Ica, Huancavelica, Ayacucho y quizás Apurimac y Cuzco. La franja intermedia pudo comprender la costa de los valles de Mala y Chincha y sus vertientes, y el valle interandino del Mantaro. Es interesante señalar que Zaferson (s.f) señala que en algunos lugares del valle del Mantaro el anako y la manta son parte de la vestimenta femenina.

Durante el Horizonte Medio (600 - 1000 d.C.), periodo de predominio Huari, el aru habría presentado tres grandes ramas, que Torero denomina: "Yauyos (abarca el sector intercalar quechua-aru, aquí es donde se habla el jaqaru), Chocorbos (vehículo de la relación idiomática y cultural entre Ica y Ayacucho-Viñaque), y Lucanas (la rama netamente nasquense de la que provendría luego los hahuasimis)" (Torero 2002: 21). En esta época tuvo lugar la división del quechua en Huáyhuash y en Yúngay. El quechua Yúngay se extiende hacia el sur y conquista territorios que antes estuvieron bajo el dominio aru.

En el Intermedio Tardío (1100-1400 d.C.) los Yauyos (aru) avanzan hacia el norte conquistando la provincia de Huarochirí y quizás la de Canta. Los Chocorbos se subdividen en tres ramas de alcance regional: vilcas, en torno a la cuenca del río Pampas, cuyo componente principal o único fue el aymara; cundi, que fue el idioma de los pueblos 'quichuas' de los actuales departamentos de Apurimac y Cuzco y parte de Arequipa; Chumbivilcas, idioma de Chumbivilcas, en el departamento de Cuzco. En estas tres áreas se usaba de forma paralela el idioma quichua del Inca. La rama Lucanas, cuyos grupos ocupaban algunas provincias del departamento de Ayacucho, varias de ellas volcadas hacia la cuenca del Pampas, principalmente hacia las vertientes de los ríos costeños de Nazca y Acarí, se segmentó en diversos dialectos. A partir de este punto los aymaras tratan de conquistar el Collao y Charcas imponiendo su idioma: el aymara. Esta conquista del aymara se cristaliza y se origina en torno de la cuenca del Pampas. Según Torero, en el siglo XVI el aymara se hallaba acorralado por el quechua y en vías de desalojo, pero no existe en esta zona una relación lingüística que los precediera, en cambio sí hay evidencia de idiomas arus "antiquísimos" que aún compartían la zona de los Andes Centrales.

\section{REFLEXIONES FINALES}

Como hemos podido observar a lo largo de este artículo, el actual poblado de Tupe es un lugar de suma importancia para el entendimiento de la etnia yauyos. A partir de las evidencias materiales y el estudio de costumbres ancestrales podemos obtener información diversa sobre la vida cotidiana y sobre todo sobre la religión e ideología de los antiguos yauyos.

Las cistas funerarias de las laderas del Tupinachaca proporcionan una serie de datos no solo del ritual funerario sino de su importancia como Apu. El patrón de las estructuras funerarias es compartida por otros sitios yauyos entre los valles del Chillón y Cañete, más no así su ubicación al interior de hendiduras o pequeños abrigos, lo cual los integra mucho más con el cerro-Apu.

Las pictografías contribuyen al conocimiento de la ideología (deidades y isacrificios?) y religión yauyos y suma ciertos datos sobre posibles actividades económicas como el pastoreo 
y el comercio mediante caravanas de camélidos en épocas prehispánicas. Hay que recordar la importante ubicación de Tupe en la cabecera de Cañete y el actual uso ritual de camélidos en la zona como parte de ceremonias diversas. Lamentablemente el estudio del arte rupestre en el Perú se encuentra en una etapa inicial, limitando el desarrollo de nuestra investigación.

Las evidencias recogidas por Tello (1929), además del hallazgo del "altar lítico" del Tupinachaca (laja con cinco orificios), nos llevan a afirmar una ocupación formativa en el sitio, lo que constituye una información poco común para los valles medios y altos de la costa central. Esto señalaría que el cerro Tupinachaca tuvo una importancia permanente para los habitantes del alto Cañete y alrededores. Fue tan importante y fuerte el significado del Apu y la totalidad de la ideología yauyos que muchos de sus elementos se mantuvieron durante los tiempos de la conquista mediante el sincretismo de deidades locales con deidades foráneas como san Bartolomé y la virgen de la Candelaria.

Por ello, el poblado actual de Tupe y los restos arqueológicos en su entorno son fuente de información importantísima para reconstruir el pasado no solo de los antiguos pobladores del río Cañete sino de toda la parte media y alta de los valles limeños, área poco estudiada tanto por arqueólogos como por etnohistoriadores.

Alrededor de la década de 1950 surgió interés por el estudio de la lengua jaqaru conservada en Tupe. Muchos lingüistas fueron atraídos por ella y esta comunidad, lo que no ocurrió con los antropólogos y sobre todo los arqueólogos (salvo Julio C. Tello), a pesar del enorme material disponible para las investigaciones.

En los últimos 50 años se ha ido perdiendo el uso del anako y parte del adorno de la vestimenta (tupus y piñes) y de la persona (aretes "tres caídas"), y el jaqaru ha dejado de ser la lengua materna para convertirse en la segunda lengua de los tupinos. Es evidente que la pérdi- da de los usos y costumbres se acentuará con la construcción de la "carretera" que propiciará un mayor contacto con las poblaciones "modernas" que rodean Tupe, haciendo que se incorporen nuevas costumbres desplazando a las nativas. Los tupinos han vivido en tal aislamiento que temen la llegada de la "carretera", pues creen que se les podría quitar o destruir sus chacras, único sustento de subsistencia. Por ello afirman que: "sería mejor que sólo llegue hasta Aiza, desde alli nosotros podemos comercializar nuestros productos con las demás zonas".

\section{Agradecimientos}

Al pueblo de Tupe por acogernos y en especial a las personas que colaboraron con nosotros en todo momento, brindándonos la información que solicitábamos; en particular queremos agradecer a las señoras Angélica Casas, Alcisa Cuevas Flores, Teodolinda Sanabria, Delia Acevedo, y la profesora Mariella Iturrizaga, quienes hicieron posible nuestro mejor entendimiento de la vestimenta tupina. También agradecemos a nuestros amigos colombianos Daniel Restrepo y Juliana Wild, con quienes compartimos información y amenas charlas. Al arql. Sergio Barraza por su ayuda desinteresada e invalorable en la búsqueda de fuentes etnohistóricas, a la arqla. Glenda Escajadillo, la Dra. Paloma Carcedo, a la Lic. Lucía Balbuena y a María Elena Elizalde por sus aportes a nuestra investigación.

\section{BibLIOGRAFía}

Ávalos de Matos, Rosalía

1952 "El ciclo vital en la comunidad de Tupe". Separata de la Revista del Museo Nacional T. XXI. Instituto de Etnología. Publicación No. 5. Universidad Nacional Mayor de San Marcos. Facultad de Letras. Lima.

Cerrón-Palomino, Rodolfo

1998 Examen de la teoría aimarista de Uhle. En: Max Uhle y el Perú antiguo. Peter 
Kaulicke editor, pp. 85-122. Lima, Fondo Editorial de la Pontificia Universidad Católica del Perú.

2000 "El origen centro andino del aimara".

En: Boletín de Arqueología PUCP 4: 131-142. Lima.

Cummins, Thomas

2003 "Imitación e invención en el Barroco Peruano". En: El Barroco Peruano. Tomo 2. Colección Arte y Tesoros del Perú. Banco de Crédito. pp. 27-59. Lima.

Del Busto Duthurburu, José Antonio

1994 La Conquista. En: Historia General del Perú. Tomo IV. Editorial Brasa, Lima.

Del Carpio, Martín; Martín Mac Kay; Raphael Santa Cruz

2001 "Poro Poro: Agua y religión en el Formativo de la sierra norte peruana". Arqueológicas 24: 95-116. Lima.

Delgado de Thays, Carmen

1959 "Religión y magia en Tupe (Yauyos)". Tesis para presentar el titulo de Doctor en la especialidad de Etnología. UNMSM. Lima.

Flores Ochoa, Jorge; Elizabeth Kuon y Roberto

Samanez

1998 Qeros. Arte Inka en vasos ceremoniales. Colección Arte y Tesoros del Perú. Lima, Banco de Crédito del Perú.

Guamán Poma de Ayala, Felipe

1993 Nueva Coronica y Buen Gobierno. Tomo I. Edición y prólogo de Franklin Pease G.Y. México D.F., Fondo de Cultura Económica.

Hardman, Martha

1983 Jaqaru. Compendio de estructura fonológica y morfológica. Instituto de Estudios Peruanos, Instituto Indigenista Interamericano. Serie Lengua y Sociedad 5. Lima.

Jesuita Anónimo

1992 "Relación de las costumbres an- tiguas de los naturales del Perú". En, Antigüedades del Perú. Enrique Urbano y Ana Sánchez editores, pp. 43-122. Madrid 1595.

Mac Kay, James

2000 Clans Eु Tartans of Scotland. Nueva York, Gramercy Books.

Matos Mar, José

1951 La ganadería en la comunidad de Tupe. Instituto de Etnología UNMSM. Publicación 2. Lima.

1956 "Yauyos, Tupe y el idioma Kauke". Separata de la Revista del Museo Nacional, Tomo XXV. Instituto de Etnología y Arqueología. Publicación 12. Universidad Nacional Mayor de San Marcos. Facultad de Letras. Lima.

Polia, Mario

1999 La cosmovisión religiosa andina en los documentos Inéditos del Archivo Romano de la Compañía de Jesús (1581-1752). Lima Fondo editorial de la Pontificia Universidad Católica del Perú.

Raimondi, Antonio

1939 Minerales del Perú. Descripción mineralógica detallada de 1617, muestra de la República, tomo II. Publicado por el Supremo Gobierno del Perú.

Rostworowski, María

2002 El avance de los Yauyos hacia la costa en tiempos míticos. Obras completas, pp. 205-214. Lima.

Salazar, Humberto y César Landa

1993 "Geología de los cuadrángulos de Mala, Lunahuaná, Tupe, Conayco, Chincha, Tantará y Castrovirreyna". República del Perú. Sector Energía y Minas, Instituto Geológico Minero y Metalúrgico. Boletín 44. Serie A Carta Geológica Nacional. Lima.

Tello, Julio C.

1929 Antiguo Perú: Primera época. Lima.

Tello, Julio C. y Toribio Mejía Xesspe

1979 "Las lenguas del centro andino". En, 
Paracas, Segunda Parte, Cavernas y Necrópolis, pp. 7-29. Publicación Antropológica del Archivo Julio C. Tello de la UNMSM. Lima.

Torero, Alfredo

2000 "El marco histórico-geográfico en la interacción quechua-aru". En, Escritura y pensamiento 3 (5): 9-58. Revista de la Unidad de Investigación de la Facultad de Letras y Ciencias Humanas de la UNMSM. Lima.

2002 Idiomas de los Andes. Lingüística e Historia. Lima, IFEA y Editorial Horizonte.

Valcárcel, Luis E.

1985 Historia del Perú antiguo a través de la fuente escrita. Vol. 6. Lima, Juan Mejía Baca editores.

Velarde, Beatrice

2002 "Tupe: rinconcito Limeño". Caretas 1719: 98-100. Lima.

Vetter, Luisa

2004 Las Piezas de Metal del Museo de Sitio Arturo Jiménez Borja - Puruchuco. En: Puruchuco y la Sociedad de Lima: un homenaje a Arturo Jiménez Borja. Luis Felipe Villacorta, Luisa Vetter y Carlos Ausejo editores.
2007 "La evolución del Tupu en forma y manufactura desde los incas hasta el Siglo XIX". 51Congreso Internacional de Americanistas, Santiago de Chile, Chile, julio, 2003. Simposio: Metalurgia en la América Antigua. En: Metalurgia en la América Antigua. Teoría, arqueología y tecnología de los metales prehispánicos. Editor científico: Roberto Lleras. Fundación de Investigaciones Arqueológicas Nacionales, Banco de la República de Colombia y el Instituto Francés de Estudios Andinos, número 253 de la Serie "Travaux" de IFEA. pp. 101128.

Villar Córdoba, Pedro

1935 Las culturas prehispánicas del departamento de Lima: Homenaje al IV Centenario de la fundación de Lima o antigua Ciudad de los Reyes. Lima.

\section{Zaferson, Olga}

s.f. Vestimenta andina: identidad y la mujer. http://home.maine.rr.com/lz/ OlgaZaferson/articulos_archivos/art 2.htm 